Methods of Functional Analysis and Topology

Vol. 26 (2020), no. 2, pp. 141-166

https://doi.org/10.31392/MFAT-npu26_2.2020.06

\title{
ON A NEW CLASS OF OPERATORS RELATED TO QUASI-FREDHOLM OPERATORS
}

\author{
ZIED GARBOUJ AND HAÏKEL SKHIRI
}

\begin{abstract}
In this paper, we introduce a generalization of quasi-Fredholm operators [7] to $k$-quasi-Fredholm operators on Hilbert spaces for nonnegative integer $k$. The case when $k=0$, represents the set of quasi-Fredholm operators and the meeting of the classes of $k$-quasi-Fredholm operators is called the class of pseudoquasi-Fredholm operators. We present some fundamental properties of the operators belonging to these classes and, as applications, we prove some spectral theorem and finite-dimensional perturbations results for these classes. Also, the notion of new index of a pseudo-quasi-Fredholm operator called $p q$-index is introduced and the stability of this index by finite-dimensional perturbations is proved. This paper extends some results proved in [5] to closed unbounded operators.
\end{abstract}

\section{INTRODUCTION AND TERMINOLOGY}

Let $\mathrm{H}$ be a Hilbert space and let $T: \mathrm{D}(T) \subseteq \mathrm{H} \longrightarrow \mathrm{H}$ be an unbounded operator with domain $\mathrm{D}(T)$. We denote by $\operatorname{ker}(T)$ the kernel of $T, \alpha(T)=\operatorname{dim} \operatorname{ker}(T)$ the nullity of $T, \operatorname{Im}(T)=T(\mathrm{H})$ the range of $T$ and $\beta(T)=\operatorname{dim} \mathrm{H} / \operatorname{Im}(T)$ its defect. By $\varphi(\mathrm{H})$ (resp. $\mathscr{B}(\mathrm{H})$ ) we denote the set of all closed (resp. bounded) linear operators on $\mathrm{H}$. Recall that an operator $T \in \varphi(\mathrm{H})$ is said to be s-regular (semi-regular) if $\operatorname{Im}(T)$ is closed and $\operatorname{ker}\left(T^{n}\right) \subseteq \operatorname{Im}(T)$, for all $n \geq 0$. Let $T \in \varphi(\mathrm{H})$, if $\operatorname{Im}(T)$ is closed and $\alpha(T)<+\infty$ (resp. $\beta(T)<+\infty$ ), then $T$ is called an upper semi-Fredholm (resp. a lower semi-Fredholm) operator. A semi-Fredholm operator is upper or lower semi-Fredholm. Let $\Phi_{+}(\mathrm{H})$ (resp. $\left.\Phi_{-}(\mathrm{H})\right)$ denote the set of upper (resp. lower) semi-Fredholm operators. If both $\alpha(T)$ and $\beta(T)$ are finite then $T$ is called a Fredholm operator. This class of operators is denoted by $\Phi(\mathrm{H})$. The index of a semi-Fredholm operator $T$ is defined by

$$
\operatorname{ind}(T)=\alpha(T)-\beta(T) \in \mathbb{Z} \cup\{+\infty,-\infty\},
$$

with the usual convention : $n-\infty=-\infty$ and $+\infty-n=+\infty$, for all $n \in \mathbb{N}$. Let $\sigma(T)$ (resp. $\varrho(T)$ ) denote the spectrum (resp. the resolvent set) of $T$.

An operator $T$ is called a Kato type operator if we can write $T=A \oplus S$ where $A$ is a nilpotent operator and $S$ is a s-regular one. In 1958, Kato proved that a closed semi-Fredholm operator is of Kato type. J. P. Labrousse [7] studied and characterized a new class of operators named quasi-Fredholm operators, in the case of Hilbert spaces and he proved that this class coincide with the set of Kato type operators and the Kato decomposition becomes a characterization of the quasi-Fredholm operators. But in the case of Banach spaces the Kato type operator is also quasi-Fredholm, the converse is not true. A bounded operator $T$ on a Banach space is called has a topological uniform descent for $n \geq d$ if $\operatorname{Im}(T)+\operatorname{ker}\left(T^{k}\right)=\operatorname{Im}(T)+\operatorname{ker}\left(T^{d}\right)$, for all $k \geq d$ and $\operatorname{Im}(T)+\operatorname{ker}\left(T^{d}\right)$ is closed [5, Definition 2.5, Theorem 3.2]. This class contains the bounded operators

2010 Mathematics Subject Classification. 30J99, 47A10, 47B38.

Key words and phrases. Complex Volterra operator, symbol, BMOA, spectrum.

This work is supported by LR18E16 : Analyse, Géométrie et Applications, University of Monastir (Tunisia). 
belonging to the class of quasi-Fredholm operators. We can find some examples and basic properties of topological uniform descent of bounded operators in [5].

In this paper we introduce two new classes of closed operators in Hilbert spaces, namely, k-quasi-Fredholm and pseudo-quasi-Fredholm operators. The first class is an extension of the class quasi-Fredholm operators, and the second class is the meeting of the classes of k-quasi-Fredholm operators. The study of first (resp. second) class of operators gives a new important part of the ordinary spectrum called the k-quasiFredholm (resp. pseudo-quasi-Fredholm) spectrum $\sigma_{q \Phi}^{k}(T)$ (resp. $\sigma_{q \Phi}^{\infty}(T)$ ) which is the set of all complex $\lambda$ such that $\lambda I-T$ is not k-quasi-Fredholm (resp. pseudo-quasiFredholm). Several properties like, spectrum, topological uniform descent, $p q$-index, and finite perturbation are investigated. Our paper is organized as follows :

In Section 2, we are interested to know the relationship of pseudo-quasi-Fredholm operators and operators having topological uniform descent. We show that the class of pseudo-quasi-Fredholm operators is not stable by the adjoint.

In Sections 3 and 4, we are interested in the spectral theory of k-quasi-Fredholm and pseudo-quasi-Fredholm. We show that they are closed subsets of the spectrum, and that for $T \in \mathscr{B}(\mathrm{H}), \sigma_{q \Phi}^{\infty}(T)$ (resp. $\sigma_{q \Phi}^{k}(T)$ ) is empty precisely when $T$ is algebraic. We also show a spectral mapping theorem for pseudo-quasi-Fredholm operators, more precisely in Theorem 4.12, for $T \in \Gamma(\mathrm{H})$ (see page 149) and $P$ is a non-constant complex polynomial, we prove that $P\left(\sigma_{q \Phi}^{\infty}(T)\right)=\sigma_{q \Phi}^{\infty}(P(T))$ and $\sigma_{q \Phi}^{k}(P(T)) \subseteq P\left(\sigma_{q \Phi}^{k}(T)\right)$, for $k \in \mathbb{N}$. Furthermore, in Theorem 4.16, we prove that if $T \in \mathscr{B}(\mathrm{H})$ and $f$ is an analytic function in a neighborhood of the usual spectrum $\sigma(T)$ and not locally constant in $\sigma(T)$, then $f\left(\sigma_{q \Phi}^{\infty}(T)\right)=\sigma_{q \Phi}^{\infty}(f(T))$ and $\sigma_{q \Phi}^{k}(f(T)) \subseteq f\left(\sigma_{q \Phi}^{k}(T)\right)$, for $k \in \mathbb{N}$ (in particular, the topological uniform descent spectrum of a bounded operator on a Hilbert space satisfies the spectral mapping theorem).

In Section 5, we are concerned with the stability of the pseudo-quasi-Fredholm spectrum and the k-quasi-Fredholm spectrum under commuting finite rank perturbations. We show that the class of pseudo-quasi-Fredholm operators is not stable under commuting quasi-nilpotent perturbations. We also show that the set of all $k$-quasi-Fredholm (resp. pseudo-quasi-Fredholm) operators on a Hilbert space $\mathrm{H}$ is not open in $\mathscr{B}(\mathrm{H})$.

In Section 6, we introduce, $\operatorname{ind}_{p q}(T)$, the $p q$-index of a k-quasi-Fredholm operator which coincide with the usual index in the case of a semi-Fredholm operator. The aim of this section is to show that if $T$ possesses $p q$-index, then $T^{n}$ (resp. $\left.T+F\right)$ is also a k-quasiFredholm operator possesses $p q$-index and $\operatorname{ind}_{p q}\left(T^{n}\right)=n \operatorname{ind}_{p q}(T)\left(\operatorname{resp} \cdot \operatorname{ind}_{p q}(T+F)=\right.$ $\operatorname{ind}_{p q}(T)$ ), where $n \in \mathbb{N} \backslash\{0\}$ and $T, F \in \mathscr{B}(\mathrm{H})$ such that $T F=F T$ and $\operatorname{dim} \operatorname{Im}(F)<$ $+\infty$. We also show that if $T \in \mathscr{B}(\mathrm{H})$ is k-quasi-Fredholm and $V \in \mathscr{B}(\mathrm{H})$ commutes with $T$ such that $V-T$ is invertible (resp. $V$ is pseudo-quasi-Fredholm) and that $V-T$ is small in norm, then $T$ possesses $p q$-index if and only if $V$ is semi-Fredholm (resp. $V$ possesses $p q$-index). In this case $\operatorname{ind}_{p q}(T)=\operatorname{ind}(V)\left(\operatorname{resp} \cdot \operatorname{ind}_{p q}(T)=\operatorname{ind}_{p q}(V)\right)$.

Finally, in Section 7, as an application, some examples are given to illustrate our theorems.

\section{Definitions And first Results}

For $T \in \varphi(\mathrm{H})$, we consider the sequence

$$
S_{j}^{k}(T)=\left(\operatorname{Im}\left(T^{j}\right) \cap \operatorname{ker}\left(T^{k+1}\right)+\operatorname{ker}\left(T^{k}\right)\right) /\left(\operatorname{Im}\left(T^{j+1}\right) \cap \operatorname{ker}\left(T^{k+1}\right)+\operatorname{ker}\left(T^{k}\right)\right),
$$

$j, k \in \mathbb{N}$. For $k \in \mathbb{N}$, we denote

$$
q_{k}(T)=\inf \left\{n \in \mathbb{N}: S_{j}^{k}(T)=0, \forall j \geq n\right\},
$$

where the infimum over the empty set is taken to be infinite.

We have the following lemma, which will be needed in the sequel. 
Lemma 2.1. Let $k \in \mathbb{N}$ and $T \in \varphi(\mathrm{H})$, then

$$
\begin{aligned}
q_{k}(T) & =\inf \left\{m \in \mathbb{N}: \operatorname{Im}(T)+\operatorname{ker}\left(T^{k+n}\right)=\operatorname{Im}(T)+\operatorname{ker}\left(T^{k+m}\right), \quad \forall n \geq m\right\} \\
& =\max \left\{q_{0}(T)-k, 0\right\} .
\end{aligned}
$$

Proof. Let $k \in \mathbb{N}$ and $\widetilde{T_{k}}$ be the operator induced by $T$ on $\mathrm{H} / \operatorname{ker}\left(T^{k}\right)$. It is easy to see that

$$
\begin{gathered}
\operatorname{ker}\left[\left(\widetilde{T_{k}}\right)^{n}\right]=\operatorname{ker}\left(T^{k+n}\right) / \operatorname{ker}\left(T^{k}\right), \\
\operatorname{Im}\left[\left(\widetilde{T_{k}}\right)^{n}\right]=\left[\operatorname{Im}\left(T^{n}\right)+\operatorname{ker}\left(T^{k}\right)\right] / \operatorname{ker}\left(T^{k}\right),
\end{gathered}
$$

for all $n \in \mathbb{N}$. This gives that

$$
\begin{gathered}
\operatorname{ker}\left(\widetilde{T_{k}}\right) \cap \operatorname{Im}\left({\widetilde{T_{k}}}^{n}\right)=\left(\left[\operatorname{Im}\left(T^{n}\right)+\operatorname{ker}\left(T^{k}\right)\right] \cap \operatorname{ker}\left(T^{k+1}\right)\right) / \operatorname{ker}\left(T^{k}\right) \\
=\left(\operatorname{Im}\left(T^{n}\right) \cap \operatorname{ker}\left(T^{k+1}\right)+\operatorname{ker}\left(T^{k}\right)\right) / \operatorname{ker}\left(T^{k}\right), \\
\operatorname{Im}\left(\widetilde{T_{k}}\right)+\operatorname{ker}\left({\widetilde{T_{k}}}^{n}\right)=\left[\operatorname{Im}(T)+\operatorname{ker}\left(T^{n+k}\right)\right] / \operatorname{ker}\left(T^{k}\right) .
\end{gathered}
$$

From [4, Lemma 2.3], (1) and (2), it follows that

$$
\begin{aligned}
q_{k}(T) & =\inf \left\{m \in \mathbb{N}: \operatorname{ker}\left(\widetilde{T_{k}}\right) \cap \operatorname{Im}\left({\widetilde{T_{k}}}^{n}\right)=\operatorname{ker}\left(\widetilde{T_{k}}\right) \cap \operatorname{Im}\left(\widetilde{T}_{k}^{m}\right), \forall n \geq m\right\} \\
& =\inf \left\{m \in \mathbb{N}: \operatorname{Im}\left(\widetilde{T}_{k}\right)+\operatorname{ker}\left(\widetilde{T}_{k}\right)=\operatorname{Im}\left(\widetilde{T}_{k}\right)+\operatorname{ker}\left(\widetilde{T}_{k}\right), \forall n \geq m\right\} \\
& =\inf \left\{m \in \mathbb{N}: \operatorname{Im}(T)+\operatorname{ker}\left(T^{k+n}\right)=\operatorname{Im}(T)+\operatorname{ker}\left(T^{k+m}\right), \quad \forall n \geq m\right\} .
\end{aligned}
$$

So we deduce that if $k \geq q_{0}(T)$, then $q_{k}(T)=0$ and if $k<q_{0}(T)$, then $q_{0}(T)=q_{k}(T)+k$. This proves that $q_{k}(T)=\max \left\{q_{0}(T)-k, 0\right\}$. The proof is complete.

The following definition describes the first class of operators we will study.

Definition 2.2. Let $k \in \mathbb{N}$. An operator $T \in \varphi(\mathrm{H})$ is called k-quasi-Fredholm of degree $d(d \in \mathbb{N})$ if :

(i) $q_{k}(T)=d$;

(ii) $\operatorname{Im}\left(T^{d}\right) \cap \operatorname{ker}\left(T^{k+1}\right)+\operatorname{ker}\left(T^{k}\right)$ is closed in $\mathrm{H}$;

(iii) $\operatorname{Im}(T)+\operatorname{ker}\left(T^{d+k}\right)$ is closed in $\mathrm{H}$.

In the sequel $k-q \Phi(d)(\mathrm{H})$, will denote the set of k-quasi-Fredholm operators of degree $d$. If there is an integer $d \in \mathbb{N}$ such that $T \in \mathrm{k}-q \Phi(d)(\mathrm{H})$, then $T$ is called a k-quasi-Fredholm operator. We will denote by $\mathrm{k}-q \Phi(\mathrm{H})$ the set of k-quasi-Fredholm operators.

Remark 2.3. Definition 2.2 generalize the well-known notion of a quasi-Fredholm operator (see [7, Definition 3.1.2]), since a quasi-Fredholm operator is a 0-quasi-Fredholm operator.

The following definition describes the second class of operators we will study.

Definition 2.4. Let $T \in \varphi(\mathrm{H})$. Then $T$ is called a pseudo-quasi-Fredholm operator if there is an integer $k \in \mathbb{N}$ such that $T \in k-q \Phi(\mathrm{H})$. By $p q \Phi(\mathrm{H})$ we denote the set of all pseudo-quasi-Fredholm operators.

The following example shows that the class of quasi-Fredholm operators is a proper subclass of pseudo-quasi-Fredholm operators.

\section{Example 2.5.}


(i) Let $\mathrm{H}$ be a Hilbert space with an orthonormal basis $\left\{e_{i, j}: i, j \in \mathbb{N} \backslash\{0\}\right\}$ and let $T$ be the operator defined by

$$
T e_{i, j}=\left\{\begin{array}{cl}
0 & \text { if } j=1, \\
\frac{e_{i, 1}}{i+1} & \text { if } j=2, \\
e_{i, j-1} & \text { otherwise. }
\end{array}\right.
$$

We denote by $\mathbf{M}$ (resp. $\mathbf{N}$ ), the vector subspace generated by $\left(e_{i, j}\right)_{i \geq 1, j \geq 2}$ (resp. $\left.\left(e_{i, 2}\right)_{i \geq 1}\right)$. It is easy to check that $\operatorname{Im}(T)=\mathrm{M}+T(\mathrm{~N}), T(\mathrm{M})=\mathrm{M}+T(\mathrm{~N})$ and $T^{2}(\mathrm{~N})=\{0\}$. Therefore $\operatorname{Im}(T)=\operatorname{Im}\left(T^{2}\right)$. Since for all $i \geq 1$, we have $\left\|T\left(e_{i, 2}\right)\right\|=$ $\frac{1}{i+1}$, then $\operatorname{Im}(T)$ is not closed. Hence $\operatorname{Im}\left(T^{n}\right)$ is not closed for all $n \geq 1$ and so $T$ is not quasi-Fredholm (see, [7, Corollary 3.3.1]). We have $\operatorname{Im}(T)+\operatorname{ker}(T)=\mathrm{H}$, so by Lemma 2.1, we deduce that $T \in 1-q \Phi(0)(\mathrm{H})$.

(ii) Let $\mathrm{H}$ be a separable Hilbert space and let $K \in \mathscr{B}(\mathrm{H})$ such that $\operatorname{Im}(K)$ is not closed. Consider the bounded operator $T: \bigotimes_{i=0}^{\infty} \mathrm{H} \longrightarrow \bigotimes_{i=0}^{\infty} \mathrm{H}$ defined by $T\left(h_{0}, h_{1}, h_{2}, \ldots\right)=$ $\left(K\left(h_{1}\right), h_{2}, h_{3}, \ldots\right)$. Clearly, $\operatorname{Im}\left(T^{2}\right)=\operatorname{Im}(T)$ is not closed and as in $(i)$, we prove that $T$ is 1-quasi-Fredholm but $T$ is not a quasi-Fredholm operator.

Remark 2.6. For $k \in \mathbb{N}$, we note from Lemma 2.1 that $q_{k}(T)=0$ if and only if $q_{0}(T) \leq k$, and hence a bounded operator has a topological uniform descent for $n \geq k$ is a k-quasi-Fredholm operator of zero degree.

Recall that $P(T) \in \varphi(\mathrm{H})$ for every complex polynomial $P$ whenever $\varrho_{e}^{+}(T)=\{\lambda \in$ $\left.\mathbb{C}: \lambda I-T \in \Phi_{+}(\mathrm{H})\right\} \neq \emptyset$.

In the following proposition, we establish the link between pseudo-quasi-Fredholm operators and operators having a topological uniform descent.

Proposition 2.7. Let $T \in \varphi(\mathrm{H})$ such that $\varrho_{e}^{+}(T) \neq \emptyset$. The following statements are equivalent :

(i) $T \in p q \Phi(\mathrm{H})$

(ii) $q_{0}(T)<+\infty$ and $\operatorname{Im}(T)+\operatorname{ker}\left(T^{q_{0}(T)}\right)$ is closed.

So the set of bounded operators belonging to the class of pseudo-quasi-Fredholm coincides with the class of bounded operators having topological uniform descent in Hilbert spaces.

Proof. " $(i) \Longrightarrow($ ii $) "$ Let $k, d \in \mathbb{N}$ such that $T \in k-q \Phi(d)(\mathrm{H})$, then by Lemma 2.1, we have $d+k \geq q_{0}(T)$ and $\operatorname{Im}(T)+\operatorname{ker}\left(T^{q_{0}(T)}\right)=\operatorname{Im}(T)+\operatorname{ker}\left(T^{d+k}\right)$ is closed.

$"(i i) \Longrightarrow(i) "$ We note first that $\operatorname{ker}\left(T^{n}\right)$ is closed for all $n \in \mathbb{N}$ because $\varrho_{e}^{+}(T) \neq \emptyset$. Let $k=q_{0}(T)$, by Lemma 2.1, we get $q_{k}(T)=0$ and hence $T \in k-q \Phi(0)(\mathrm{H})$. This completes the proof.

The techniques used in this work are based in the concept of paracomplete subspaces of Hilbert spaces (see, [7, Chapter II]).

Definition 2.8 ([7], Definition 2.1.1, Definition 2.1.2).

(i) A subspace $\mathrm{M}$ of $\mathrm{H}$ is said to be paracomplete in $\mathrm{H}$, if $\mathrm{M}$ is a Banach space and the canonical injection of $\mathrm{M}$ in $\mathrm{H}$ is continuous. In particular, a closed subspace of a Hilbert space $\mathrm{H}$ is a paracomplete subspace of $\mathrm{H}$.

(ii) An operator $T: \mathrm{D}(T) \subseteq \mathrm{H} \longrightarrow \mathrm{H}$ is called paracomplete if its graph is a paracomplete subspace of $\mathrm{H} \times \mathrm{H}$. It is clear that a closed operator in a Hilbert space $\mathrm{H}$ is a paracomplete operator in $\mathrm{H}$. 
The following lemma follows immediately from [7, Proposition 2.2 page 183] and [7, Proposition 2.1.3, Proposition 2.1.4].

Lemma 2.9. Let $T: \mathrm{D}(T) \subseteq \mathrm{H} \longrightarrow \mathrm{H}$ be a paracomplete operator and let $k, i, n \in \mathbb{N}$. Then $\mathrm{D}\left(T^{k}\right), \operatorname{Im}\left(T^{k}\right), \operatorname{ker}\left(T^{k}\right), \operatorname{ker}\left(T^{k}\right)+\operatorname{Im}\left(T^{n}\right)$ and $\left[\operatorname{ker}\left(T^{k}\right)+\operatorname{Im}\left(T^{n}\right)\right] \cap \operatorname{ker}\left(T^{i}\right)$ are paracomplete subspaces in $\mathrm{H}$.

The ascent and descent of $T \in \varphi(\mathrm{H})$ are defined by

$$
\begin{gathered}
\boldsymbol{a}(T)=\inf \left\{n \in \mathbb{N}: \operatorname{ker}\left(T^{n}\right)=\operatorname{ker}\left(T^{n+1}\right)\right\}, \\
\boldsymbol{d}(T)=\inf \left\{n \in \mathbb{N}: \operatorname{Im}\left(T^{n}\right)=\operatorname{Im}\left(T^{n+1}\right)\right\},
\end{gathered}
$$

respectively, whenever these minima exist. If no such numbers exist the ascent and descent of $T$ are defined to be $+\infty$. The notion of ascent and descent was studied in several articles ([4], [8], [11]). Let $d$ be a positive integer, from [11], we mention the following useful characterizations :

$$
\begin{gathered}
\boldsymbol{a}(T) \leq d \Longleftrightarrow \operatorname{Im}\left(T^{d}\right) \cap \operatorname{ker}\left(T^{n}\right)=\{0\} \quad \text { for some (equivalently all) } n \geq 1, \\
\boldsymbol{d}(T) \leq d \Longleftrightarrow \mathrm{D}\left(T^{d}\right) \subseteq \operatorname{Im}\left(T^{n}\right)+\operatorname{ker}\left(T^{d}\right) \quad \text { for some (equivalently all) } n \geq 1 .
\end{gathered}
$$

\section{Remark 2.10.}

(i) An operator $T \in \mathscr{B}(\mathrm{H})$ such that $\boldsymbol{d}(T)<+\infty$ and $\operatorname{Im}\left(T^{\boldsymbol{d}(T)}\right)$ is not closed is a pseudo-quasi-Fredholm operator but is not a quasi-Fredholm operator (see Example $2.5)$.

(ii) Let $k \in \mathbb{N} \backslash\{0\}$. We know that if $T \in q \Phi(\mathrm{H})$, then $\operatorname{Im}\left(T^{n}\right)$ is closed for all $n \geq q_{0}(T)$, but if $T \in k-q \Phi(\mathrm{H})$, we cannot conclude that $\operatorname{Im}\left(T^{n}\right)$ is closed for some $n>q_{k}(T)$ (see Example 2.5).

(iii) In operators theory, if $T$ is semi-Fredholm (resp. semi-regular, quasi-Fredholm; $\ldots$ ) and its domain is a dense subset of $\mathbf{H}$, then its adjoint $T^{*}$ is also semiFredholm (resp. semi-regular, quasi-Fredholm; ...). Unfortunately, this is not the case for pseudo-quasi-Fredholm operators. In Example 2.5, the operator $T$ is pseudo-quasi-Fredholm, but its adjoint $T^{*}$ is not pseudo-quasi-Fredholm. In fact, if $T^{*}$ is pseudo-quasi-Fredholm, then $T^{*} \in k-q \Phi(d)(\mathrm{H})$, for some $k, d \in \mathbb{N}$. Hence $\operatorname{Im}\left(T^{*}\right)+\operatorname{ker}\left(T^{* k+d}\right)$ is closed. Since $\operatorname{Im}\left(T^{2}\right)=\operatorname{Im}(T)$, it follows that $\operatorname{ker}\left(T^{* 2}\right)=$ $\operatorname{ker}\left(T^{*}\right)$ and so $\boldsymbol{a}\left(T^{*}\right) \leq 1$. Therefore $\operatorname{Im}\left(T^{*}\right)+\operatorname{ker}\left(T^{*}\right)=\operatorname{Im}\left(T^{*}\right)+\operatorname{ker}\left(T^{* k+d}\right)$ is closed and $\operatorname{Im}\left(T^{*}\right) \cap \operatorname{ker}\left(T^{*}\right)=\{0\}\left(k \geq 1\right.$ because $T^{*}$ is not quasi-Fredholm). From [7, Proposition 2.1.1] and Lemma 2.9, we can see that $\operatorname{Im}\left(T^{*}\right)$ is closed. Hence $\operatorname{Im}(T)$ is closed, which is a contradiction. Consequently, $T^{*}$ is not pseudo-quasi-Fredholm.

Let $\mathrm{M}$ be a closed subspace of $\mathrm{H}$, then $\mathrm{H} / \mathrm{M}$ is a Hilbert space with the following scalar product

$$
\begin{aligned}
\langle\cdot, \cdot\rangle_{\mathrm{M}}: \mathrm{H} / \mathrm{M} \times \mathrm{H} / \mathrm{M} & \longrightarrow \mathbb{R} \\
(\bar{x}, \bar{y}) & \longmapsto\langle P(x), P(y)\rangle,
\end{aligned}
$$

where $P$ is the orthogonal projection on $\mathrm{M}^{\perp}$ and $\langle\cdot, \cdot\rangle$ is the scalar product of $\mathrm{H}$. Note that the topology in the Hilbert space $\left(\mathrm{H} / \mathrm{M},\langle\cdot, \cdot\rangle_{\mathrm{M}}\right)$ coincides with the quotient topology in $\mathrm{H} / \mathrm{M}$ :

$$
\|\bar{x}\|=\sqrt{\langle\bar{x}, \bar{x}\rangle_{\mathrm{M}}}=\sqrt{\langle P(x), P(x)\rangle}=\operatorname{dist}(x, \mathrm{M}),
$$

where $\operatorname{dist}(x, \mathrm{M})$ is the distance of $x$ to $\mathrm{M}$. In particular, if $T \in \varphi(\mathrm{H}) \operatorname{such}$ that $\operatorname{ker}\left(T^{k}\right)$ is closed for $k \in \mathbb{N}$, then $\mathbf{H} / \operatorname{ker}\left(T^{k}\right)$ is a Hilbert space. For $k \in \mathbb{N}$, let $\widetilde{T_{k}}$ denote the following operator

$$
\begin{aligned}
\widetilde{T_{k}}: \quad \mathrm{D}\left(\widetilde{T_{k}}\right) \subseteq \mathrm{H} / \operatorname{ker}\left(T^{k}\right) & \longrightarrow \mathrm{H} / \operatorname{ker}\left(T^{k}\right) \\
\bar{x} & \longmapsto
\end{aligned}
$$


By $q \Phi(\mathrm{H})$ (resp. $q \Phi(d)(\mathrm{H})$ ) we denote the set of all quasi-Fredholm operators (resp. of degree $d)$.

Proposition 2.11. Let $T: \mathrm{D}(T) \subseteq \mathrm{H} \longrightarrow \mathrm{H}$ be a paracomplete operator and $k, d \in \mathbb{N}$ such that $\operatorname{ker}\left(T^{k}\right)$ is closed. Then

$$
T \in k-q \Phi(d)(\mathrm{H}) \Longleftrightarrow \widetilde{T_{k}} \in q \Phi(d)\left(\mathrm{H} / \operatorname{ker}\left(T^{k}\right)\right) .
$$

Proof. Define

$$
\begin{aligned}
& \pi: \mathbf{H} \times \mathbf{H} \longrightarrow\left(\mathrm{H} / \operatorname{ker}\left(T^{k}\right)\right) \times\left(\mathrm{H} / \operatorname{ker}\left(T^{k}\right)\right) \\
& (x, y) \longmapsto(\bar{x}, \bar{y}) \text {. }
\end{aligned}
$$

Since $\mathrm{G}\left(\widetilde{T_{k}}\right)$, the graph of $\widetilde{T_{k}}$ is equal to $\pi(\mathrm{G}(T))$, we deduce from [7, Proposition 2.1.4], that $\mathrm{G}\left(\widetilde{T_{k}}\right)$ is paracomplete. For all $n \in \mathbb{N}$, we have

$$
\operatorname{Im}\left(\widetilde{T_{k}}\right)+\operatorname{ker}\left({\widetilde{T_{k}}}^{n}\right)=\left[\operatorname{Im}(T)+\operatorname{ker}\left(T^{n+k}\right)\right] / \operatorname{ker}\left(T^{k}\right)
$$

and

$$
\operatorname{ker}\left(\widetilde{T_{k}}\right) \cap \operatorname{Im}\left({\widetilde{T_{k}}}^{n}\right)=\left(\operatorname{Im}\left(T^{n}\right) \cap \operatorname{ker}\left(T^{k+1}\right)+\operatorname{ker}\left(T^{k}\right)\right) / \operatorname{ker}\left(T^{k}\right) .
$$

Now by (2) we deduce that $q_{k}(T)=q_{0}\left(\widetilde{T_{k}}\right)$. If $\widetilde{T_{k}} \in q \Phi(d)\left(\mathrm{H} / \operatorname{ker}\left(T^{k}\right)\right)$, from $[7$, Remark page 205], it follows that $\widetilde{T_{k}}$ is closed. So, by [9, Lemma 1.4], there exists $\lambda \in \mathbb{C} \backslash\{0\}$ such that $\lambda I-\widetilde{T_{k}}$ is s-regular. Since $\operatorname{Im}\left(\lambda I-\widetilde{T_{k}}\right)=\operatorname{Im}(\lambda I-T) / \operatorname{ker}\left(T^{k}\right)$ and $\operatorname{ker}\left(\lambda I-\widetilde{T_{k}}\right)=$ $\left[\operatorname{ker}(\lambda I-T)+\operatorname{ker}\left(T^{k}\right)\right] / \operatorname{ker}\left(T^{k}\right)$ are closed, then by Lemma 2.9 and [7, Proposition 2.1.1], we see that $\operatorname{Im}(\lambda I-T)$ and $\operatorname{ker}(\lambda I-T)$ are also closed and consequently $T=\lambda I-(\lambda I-T)$ is closed (see, [7, Proposition 2.2.3]). So by (1) and (2), we get

$$
T \in k-q \Phi(d)(\mathrm{H}) \Longleftrightarrow \widetilde{T_{k}} \in q \Phi(d)\left(\mathrm{H} / \operatorname{ker}\left(T^{k}\right)\right) .
$$

The proof is complete.

As a direct consequence of Proposition 2.11 and [7, Remark page 205] we obtain the following result :

Corollary 2.12. Let $k \in \mathbb{N}$ and $T: \mathrm{D}(T) \subseteq \mathrm{H} \longrightarrow \mathrm{H}$ be a paracomplete operator such that

(i) $q_{k}(T)=d<+\infty$ and $\operatorname{ker}\left(T^{k}\right)$ is closed in $\mathrm{H}$,

(ii) $\operatorname{Im}\left(T^{d}\right) \cap \operatorname{ker}\left(T^{k+1}\right)+\operatorname{ker}\left(T^{k}\right)$ is closed in $\mathrm{H}$,

(iii) $\operatorname{Im}(T)+\operatorname{ker}\left(T^{d+k}\right)$ is closed in $\mathrm{H}$,

then $T$ is closed operator i.e., $T \in k-q \Phi(d)(\mathrm{H})$.

Next we proceed to obtain a necessary condition and a sufficient condition for that a $\mathrm{k}$-quasi-Fredholm operator is a quasi-Fredholm operator.

Theorem 2.13. Let $k, d \in \mathbb{N}$ and $T \in k-q \Phi(d)(\mathrm{H})$. Then

$$
T \in q \Phi(\mathrm{H}) \Longleftrightarrow \operatorname{ker}(T) \cap \operatorname{Im}\left(T^{d+k}\right) \quad \text { is closed. }
$$

Proof. By Lemma 2.1, we conclude that $q_{0}(T) \leq d+k$ and

$$
\operatorname{Im}(T)+\operatorname{ker}\left(T^{q_{0}(T)}\right)=\operatorname{Im}(T)+\operatorname{ker}\left(T^{d+k}\right)
$$

is closed. Hence

$$
T \in q \Phi\left(q_{0}(T)\right)(\mathrm{H}) \Longleftrightarrow \operatorname{ker}(T) \cap \operatorname{Im}\left(T^{q_{0}(T)}\right)=\operatorname{ker}(T) \cap \operatorname{Im}\left(T^{k+d}\right) \quad \text { is closed. }
$$

This completes the proof of the theorem. 


\section{Pseudo-quasi-Fredholm SPeCtrum And K-Quasi-Fredholm SPeCtrum}

Throughout the remainder of the paper, for $T \in \varphi(\mathrm{H})$ and $\lambda \in \mathbb{C}$, we denote by $T_{\lambda}$ the operator $\lambda I-T$.

For $k \in \mathbb{N}$, the $\mathrm{k}$-quasi-Fredholm resolvent and $\mathrm{k}$-quasi-Fredholm spectrum of an operator $T \in \varphi(\mathrm{H})$ are defined respectively by

$$
\varrho_{q \Phi}^{k}(T)=\left\{\lambda \in \mathbb{C}: T_{\lambda} \in k-q \Phi(\mathrm{H})\right\}
$$

and

$$
\sigma_{q \Phi}^{k}(T)=\mathbb{C} \backslash \varrho_{q \Phi}^{k}(T) .
$$

We denote by $\sigma_{e}(T)$ the essential quasi-Fredholm spectrum of $T$ (see [9]). We note that $\sigma_{e}(T)=\sigma_{q \Phi}^{0}(T)$. The set $\sigma_{q \Phi}^{\infty}(T):=\bigcap_{k \geq 0} \sigma_{q \Phi}^{k}(T)$ is called pseudo-quasi-Fredholm spectrum of $T$. The complementary set $\varrho_{q \Phi}^{\infty}(T)=\mathbb{C} \backslash \sigma_{q \Phi}^{\infty}(T)$ is the pseudo-quasi-Fredholm resolvent. For all $k \in \mathbb{N}$, it is clear that

$$
\varrho(T) \subseteq \varrho_{q \Phi}^{k}(T) \subseteq \varrho_{q \Phi}^{\infty}(T)
$$

If $T \in \mathscr{B}(\mathrm{H})$, it follows from Proposition 2.7 that

$$
\varrho_{q \Phi}^{\infty}(T)=\left\{\lambda \in \mathbb{C}: T_{\lambda} \text { has topological uniform descent }\right\} .
$$

Throughout this section we assume that $\varrho_{e}^{+}(T) \neq \emptyset$.

Now, we are ready to state our main result of this section, which represents an improvement of [9, Lemma 1.4] to the class of k-quasi-Fredholm operators.

Lemma 3.1. Let $d, k \in \mathbb{N}$ and $T \in k-q \Phi(d)(\mathrm{H})$, then there exists $\varepsilon>0$ such that for all $\lambda \in \mathbb{C}, 0<|\lambda|<\varepsilon:$

(i) $T_{\lambda}$ is a s-regular operator,

(ii) $\alpha\left(T_{\lambda}\right)=\operatorname{dim} \operatorname{ker}(T) \cap \operatorname{Im}\left(T^{d+k}\right)$,

(iii) $\beta\left(T_{\lambda}\right)=\operatorname{dim} \mathrm{H} /\left[\operatorname{Im}(T)+\operatorname{ker}\left(T^{d+k}\right)\right]$.

Proof. From Proposition 2.11, we know that $\widetilde{T_{k}} \in q \Phi(d)\left(\mathrm{H} / \operatorname{ker}\left(T^{k}\right)\right)$. We apply now $[9$, Lemma 1.4], we deduce that there exists $\varepsilon>0$ such that for all $\lambda \in \mathbb{C}, 0<|\lambda|<\varepsilon$, we have

$$
\begin{gathered}
\lambda I-\widetilde{T_{k}} \text { is s-regular, } \\
\alpha\left(\lambda I-\widetilde{T_{k}}\right)=\operatorname{dim}\left(\operatorname{ker}\left(\widetilde{T_{k}}\right) \cap \operatorname{Im}\left({\widetilde{T_{k}}}^{d}\right)\right), \\
\beta\left(\lambda I-\widetilde{T_{k}}\right)=\operatorname{dim}\left(\mathrm{H} / \operatorname{ker}\left(T^{k}\right)\right) /\left[\operatorname{lm}\left(\widetilde{T_{k}}\right)+\operatorname{ker}\left(\widetilde{T}_{k}^{d}\right)\right] .
\end{gathered}
$$

As $\operatorname{ker}\left(T^{k}\right) \subseteq \operatorname{Im}\left[\left(T_{\lambda}\right)^{n}\right]$, we have for all $n \in \mathbb{N}$,

$$
\operatorname{Im}\left[\left(\lambda I-\widetilde{T_{k}}\right)^{n}\right]=\left[\operatorname{Im}\left[\left(T_{\lambda}\right)^{n}\right]+\operatorname{ker}\left(T^{k}\right)\right] / \operatorname{ker}\left(T^{k}\right)=\operatorname{Im}\left[\left(T_{\lambda}\right)^{n}\right] / \operatorname{ker}\left(T^{k}\right)
$$

and

$$
\operatorname{ker}\left[\left(\lambda I-\widetilde{T_{k}}\right)^{n}\right]=\left(\operatorname{ker}\left[\left(T_{\lambda}\right)^{n}\right]+\operatorname{ker}\left(T^{k}\right)\right) / \operatorname{ker}\left(T^{k}\right)
$$

(i) By (1), we obtain

$$
\operatorname{ker}\left(T_{\lambda}\right) \subseteq \operatorname{ker}\left(T_{\lambda}\right)+\operatorname{ker}\left(T^{k}\right) \subseteq \operatorname{Im}\left[\left(T_{\lambda}\right)^{n}\right], \quad \forall n \in \mathbb{N}
$$


and it follows that $\operatorname{Im}\left(T_{\lambda}\right)$ is closed. So $T_{\lambda}$ is s-regular for all $0<|\lambda|<\varepsilon$.

(ii) Since $\operatorname{ker}\left(T^{k}\right) \cap \operatorname{ker}\left(T_{\lambda}\right)=\{0\}$, it follows from (2) that

$$
\begin{aligned}
\alpha\left(T_{\lambda}\right) & =\operatorname{dim}\left[\operatorname{ker}\left(T_{\lambda}\right)+\operatorname{ker}\left(T^{k}\right)\right] / \operatorname{ker}\left(T^{k}\right) \\
& =\alpha\left(\lambda I-\widetilde{T}_{k}\right) \\
& =\operatorname{dim} \operatorname{ker}\left(\widetilde{T}_{k}\right) \cap \operatorname{Im}\left(\widetilde{T}_{k}{ }^{d}\right) \\
& =\operatorname{dim}\left(\left[\operatorname{Im}\left(T^{d}\right)+\operatorname{ker}\left(T^{k}\right)\right] \cap \operatorname{ker}\left(T^{k+1}\right)\right) / \operatorname{ker}\left(T^{k}\right) \\
& =\operatorname{dim}\left(\operatorname{Im}\left(T^{d}\right) \cap \operatorname{ker}\left(T^{k+1}\right)+\operatorname{ker}\left(T^{k}\right)\right) / \operatorname{ker}\left(T^{k}\right) \\
& =\operatorname{dim}\left(\operatorname{Im}\left(T^{d}\right) \cap \operatorname{ker}\left(T^{k+1}\right)\right) /\left(\operatorname{Im}\left(T^{d}\right) \cap \operatorname{ker}\left(T^{k}\right)\right) \\
& =\operatorname{dim} \operatorname{ker}\left(S^{k+1}\right) / \operatorname{ker}\left(S^{k}\right), \quad \operatorname{where} S=T_{\mid \operatorname{Im}\left(T^{d}\right)} \\
& =\operatorname{dim} \operatorname{ker}(S) \cap \operatorname{Im}\left(S^{k}\right) \\
& =\operatorname{dim} \operatorname{ker}(T) \cap \operatorname{Im}\left(T^{d+k}\right) .
\end{aligned}
$$

(iii) From (3), we get

$$
\begin{aligned}
\beta\left(T_{\lambda}\right) & =\beta\left(\lambda I-\widetilde{T_{k}}\right) \\
& =\operatorname{dim}\left(\mathbf{H} / \operatorname{ker}\left(T^{k}\right)\right) /\left(\operatorname{Im}\left(\widetilde{T_{k}}\right)+\operatorname{ker}\left({\widetilde{T_{k}}}^{d}\right)\right) \\
& =\operatorname{dim} \mathrm{H} /\left(\operatorname{Im}(T)+\operatorname{ker}\left(T^{d+k}\right)\right) .
\end{aligned}
$$

The proof is complete.

Corollary 3.2. Let $T \in \varphi(\mathrm{H})$ and $k \in \mathbb{N}$. Then $\sigma_{q \Phi}^{k}(T)$ and $\sigma_{q \Phi}^{\infty}(T)$ are closed.

For $T \in \varphi(\mathrm{H})$, we consider the following :

$\mathrm{E}(T)=\left\{\lambda \in \sigma(T): \lambda\right.$ an isolated point, $\boldsymbol{a}\left(T_{\lambda}\right)<+\infty$,

$$
\left.\boldsymbol{d}\left(T_{\lambda}\right)=m<+\infty \text { and } \operatorname{Im}\left[\left(T_{\lambda}\right)^{m}\right] \text { is closed }\right\} .
$$

Let's recall that if $\varrho(T) \neq \emptyset$, (see, [8, Theorem 2.1])

$$
\mathrm{E}(T)=\left\{\lambda \in \sigma(T): \boldsymbol{a}\left(T_{\lambda}\right)=\boldsymbol{d}\left(T_{\lambda}\right)<+\infty\right\} .
$$

Theorem 3.3. Let $T \in \varphi(\mathrm{H})$ and $k \in \mathbb{N}$. Then

$$
\partial \sigma(T) \cap \varrho_{q \Phi}^{k}(T)=\partial \sigma(T) \cap \varrho_{q \Phi}^{\infty}(T)=\mathrm{E}(T) .
$$

Proof. The case $\varrho(T)=\emptyset$ is trivial, so assume that $\varrho(T) \neq \emptyset$. Clearly, the following inclusions hold :

$$
\mathrm{E}(T) \subseteq \partial \sigma(T) \cap \varrho_{q \Phi}^{k}(T) \subseteq \partial \sigma(T) \cap \varrho_{q \Phi}^{\infty}(T) .
$$

For the reverse inclusions, let $\mu \in \partial \sigma(T) \cap \varrho_{q \Phi}^{\infty}(T)$, we denote by $R=\mu I-T$. Let $k, d \in \mathbb{N}$ such that $R \in k-q \Phi(d)(\mathrm{H})$. We know from Lemma 3.1, that there exists $\varepsilon>0$ such that

$$
\alpha(\lambda I-R)=\operatorname{dim} \operatorname{ker}(R) \cap \operatorname{Im}\left(R^{d+k}\right) \quad \text { and } \quad \beta(\lambda I-R)=\operatorname{dim} \mathrm{H} /\left[\operatorname{Im}(R)+\operatorname{ker}\left(R^{d+k}\right)\right],
$$

for all $0<|\lambda|<\varepsilon$. Since $\varrho(R) \cap\{\lambda \in \mathbb{C}: 0<|\lambda|<\varepsilon\} \neq \emptyset$, we deduce that

$$
\alpha(\lambda I-R)=\beta(\lambda I-R)=0, \quad \forall 0<|\lambda|<\varepsilon .
$$

This leads to $\boldsymbol{a}(R)=\boldsymbol{d}(R) \leq d+k$ and $\mu \in \mathrm{E}(T)$. This completes the proof.

We recall that $T \in \mathscr{B}(\mathrm{H})$ is called algebraic if $P(T)=0$ for some nonzero polynomial $P$. Arguing as in the proof of [2, Theorem 1.5], we get the following result :

$$
T \text { is algebraic } \Longleftrightarrow \sigma(T)=\left\{\lambda_{1}, \lambda_{2}, \ldots, \lambda_{n}\right\}=\mathrm{E}(T) .
$$

In the following theorem, we show that the operators whose k-quasi-Fredholm spectrum is empty are exactly the algebraic operators.

Theorem 3.4. Let $T \in \mathscr{B}(\mathrm{H})$ and $k \in \mathbb{N}$, then the following conditions are equivalent: 
(i) $\sigma_{q \Phi}^{k}(T)=\emptyset$;

(ii) $\sigma_{q \Phi}^{\infty}(T)=\emptyset$;

(iii) $T$ is algebraic.

Proof. " $(i) \Longrightarrow($ iii $)$ " We have $\varrho_{q \Phi}^{k}(T)=\mathbb{C}$, this implies that $\mathrm{E}(T)=\varrho_{q \Phi}^{k}(T) \cap \partial \sigma(T)=$ $\partial \sigma(T) \neq \emptyset$ and hence $\sigma(T)=\mathrm{E}(T)$. Consequently, $T$ is algebraic.

$"($ iii $) \Longrightarrow(i) " T$ is algebraic implies that $\sigma(T)=\mathrm{E}(T)=\varrho_{q \Phi}^{k}(T) \cap \partial \sigma(T) \subseteq \varrho_{q \Phi}^{k}(T)$. Therefore $\varrho_{q \Phi}^{k}(T)=\mathbb{C}$.

In the same way, we obtain the following equivalence :

$$
\sigma_{q \Phi}^{\infty}(T)=\emptyset \Longleftrightarrow T \quad \text { is algebraic. }
$$

This completes the proof of the proposition.

\section{A spectral mapping theorem For PSEUdo-Quasi-Fredholm}

For $T: \mathrm{D}(T) \subseteq \mathrm{H} \longrightarrow \mathrm{H}$, we denote by

$$
\operatorname{do}(T)=\inf \left\{n \in \mathbb{N}: \mathrm{D}\left(T^{n}\right)=\mathrm{D}\left(T^{n+1}\right)\right\}
$$

where the infimum over the empty set is taken to be $+\infty$ (see, [4, page 31]). We remark that if $\mathrm{do}(T)<+\infty$, then

$$
\mathrm{D}\left(T^{\mathrm{do}(T)}\right)=\mathrm{D}\left(T^{\mathrm{do}(T)+n}\right) \subseteq \mathrm{D}\left(T^{n}\right), \quad \forall n \in \mathbb{N} .
$$

Consequently $T\left(\mathrm{D}\left(T^{\mathrm{do}(T)}\right)\right)=T\left(\mathrm{D}\left(T^{\mathrm{do}(T)+1}\right)\right) \subseteq \mathrm{D}\left(T^{\mathrm{do}(T)}\right)$.

Of course, there exist operators such that $\operatorname{do}(T)=+\infty$ and operators such that do $(T)<+\infty$. This can be illustrated in the following example.

\section{Example 4.1.}

(i) Let $\mathbf{H}=\mathrm{L}^{2}(\mathbb{R})$ and $n \in \mathbb{N}$, we define the subspace $\mathrm{D}_{n}$ of $\mathbf{H}$ by

$$
\mathrm{D}_{n}=\left\{f \in \mathrm{H}: \int_{\mathbb{R}} t^{2 n}|f(t)|^{2} d t<+\infty\right\},
$$

and the operator $T$ by

$$
\begin{aligned}
T: \mathrm{D}(T) \subseteq \mathrm{H} & \longrightarrow \mathrm{H} \\
f & \longmapsto \psi f, \quad \text { with } \psi(t)=t .
\end{aligned}
$$

It is clear that $\mathrm{D}\left(T^{n}\right)=\mathrm{D}_{n}$ and hence $\operatorname{do}(T)=+\infty$. For $q \in \mathbb{N}$, we define

$$
\begin{aligned}
& S: \mathrm{D}(S) \subseteq \underset{f}{\mathrm{H}} / \mathrm{D}\left(T^{q}\right) \longrightarrow \mathrm{H} / \mathrm{D}\left(T^{q}\right) \\
& T(f)
\end{aligned}
$$

Since $\mathrm{D}\left(S^{q}\right)=\{0\}$ and $\mathrm{D}\left(S^{q-1}\right) \neq\{0\}$ (if $q>0$ ), then $\operatorname{do}(S)=q$.

(ii) Let $\mathrm{H}$ be a separable Hilbert space and let $K: \mathrm{D}(K) \subseteq \mathrm{H} \longrightarrow \mathrm{H}$. Consider the linear operator $T: \mathrm{D}(T) \subseteq \bigotimes_{i=0}^{\infty} \mathrm{H} \longrightarrow \bigotimes_{i=0}^{\infty} \mathrm{H}$ defined by $T\left(h_{0}, h_{1}, h_{2}, \ldots\right)=$ $\left(K\left(h_{1}\right), h_{2}, h_{3}, \ldots\right)$. Clearly, $\mathrm{D}\left(T^{k}\right)=\mathrm{H} \times \bigotimes_{i=1}^{i=k} \mathrm{D}(K) \times \bigotimes_{i=k+1}^{\infty} \mathrm{H}$. Hence do $(T)=$ $+\infty$ if $\mathrm{D}(K) \varsubsetneqq \mathrm{H}$ and do $(T)=0$ when $\mathrm{D}(K)=\mathrm{H}$.

Let us consider the following class :

$$
\begin{aligned}
\Gamma(\mathrm{H})=\{T: \mathrm{D}(T) \subseteq \mathrm{H} \longrightarrow & \mathrm{H} \text { paracomplete }: q=\mathrm{do}(T)<+\infty, \\
& \left.\mathrm{D}\left(T^{q}\right) \text { and } \operatorname{Im}\left(T_{\lambda}\right)+\mathrm{D}\left(T^{q}\right) \text { are closed, } \forall \lambda \in \mathbb{C}\right\} .
\end{aligned}
$$


It is clear that $\mathscr{B}(\mathrm{H}) \subseteq \Gamma(\mathrm{H})$. Assume that $T$ is a paracomplete operator such that $q=\operatorname{do}(T)<+\infty$. It is easy to see that if $P$ is a complex polynomial, then $P(T)$ is paracomplete and $\operatorname{do}(P(T)) \leq q$. Furthermore, if $P$ is a non-constant complex polynomial, then $\mathrm{D}\left([P(T)]^{n}\right)=\mathrm{D}\left(T^{q}\right)$, for all $n \geq \operatorname{do}(P(T))$. We will show that if $T \in \Gamma(\mathrm{H})$, then $P(T) \in \Gamma(\mathrm{H})$, for all complex polynomial $P$. Set $q=\operatorname{do}(T)$ and define

$$
\begin{aligned}
\bar{T}: \mathrm{D}(\bar{T}) \subseteq \mathrm{H} / \mathrm{D}\left(T^{q}\right) & \longrightarrow \mathrm{H} / \mathrm{D}\left(T^{q}\right) \\
\bar{T} x & \longmapsto
\end{aligned}
$$

Let $\lambda \in \mathbb{C}$ and $\bar{x} \in \operatorname{ker}(\lambda I-\bar{T})$, then $T_{\lambda} x \in \mathrm{D}\left(T^{q}\right)$. Clearly, $x \in \mathrm{D}\left(T^{q+1}\right)=\mathrm{D}\left(T^{q}\right)$ and $\bar{x}=0$, so $\operatorname{ker}(\lambda I-\bar{T})=\{0\}$. Let us remark that $\operatorname{Im}(\lambda I-\bar{T})=\left[\operatorname{Im}\left(T_{\lambda}\right)+\mathrm{D}\left(T^{q}\right)\right] / \mathrm{D}\left(T^{q}\right)$ is closed. As in the proof of Proposition 2.11, we prove that $\lambda I-\bar{T}$ is paracomplete and so by [7, Proposition 2.2.3], $\lambda I-\bar{T} \in \varphi\left(\mathrm{H} / \mathrm{D}\left(T^{q}\right)\right)$. Hence $\lambda I-\bar{T} \in \Phi_{+}\left(\mathrm{H} / \mathrm{D}\left(T^{q}\right)\right)$. Now, let $P(Z)=\left(\lambda_{1}-Z\right)^{\alpha_{1}}\left(\lambda_{2}-Z\right)^{\alpha_{2}} \cdots\left(\lambda_{m}-Z\right)^{\alpha_{m}}$ be a complex polynomial. We know that if $S, L \in \varphi(\mathrm{H})$ such that $L \in \Phi_{+}(\mathrm{H})$ and $\operatorname{Im}(S)$ is closed, then $L S \in \varphi(\mathrm{H})$ and $\operatorname{Im}(L S)$ is closed. For $i, j \in\{1,2, \ldots, m\}$, we have $\lambda_{i} I-\bar{T} \in \Phi_{+}\left(\mathrm{H} / \mathrm{D}\left(T^{q}\right)\right)$ and $\operatorname{Im}\left(\lambda_{j} I-\bar{T}\right)$ is closed, therefore $\left(\lambda_{i} I-\bar{T}\right)\left(\lambda_{j} I-\bar{T}\right) \in \varphi\left(\mathrm{H} / \mathrm{D}\left(T^{q}\right)\right)$ and $\operatorname{Im}\left[\left(\lambda_{i} I-\bar{T}\right)\left(\lambda_{j} I-\bar{T}\right)\right]$ is closed. Since $\operatorname{ker}\left[\left(\lambda_{i} I-\bar{T}\right)\left(\lambda_{j} I-\bar{T}\right)\right]=\{0\}$, then $\left(\lambda_{i} I-\bar{T}\right)\left(\lambda_{j} I-\bar{T}\right) \in \Phi_{+}\left(\mathrm{H} / \mathrm{D}\left(T^{q}\right)\right)$ and consequently $\operatorname{Im}(P(\bar{T}))=\left[\operatorname{Im}[P(T)]+\mathrm{D}\left(T^{q}\right)\right] / \mathrm{D}\left(T^{q}\right)$ is closed. Finally, we deduce that $\operatorname{Im}[P(T)]+\mathrm{D}\left(T^{q}\right)=\operatorname{Im}[P(T)]+\mathrm{D}\left[(P(T))^{\mathrm{do}(P(T))}\right]$ is closed and $P(T) \in \Gamma(\mathrm{H})$.

\section{Example 4.2.}

(i) Let $\mathrm{H}$ be a separable Hilbert space and let $K \in \varphi(\mathrm{H})$ such that $\mathrm{D}(K) \varsubsetneqq \mathrm{H}$ is closed. Let $\mathcal{H}=\bigotimes_{i=0}^{3} \mathrm{H}$ and consider the linear operator $T: \mathcal{H} \longrightarrow \mathcal{H}$ defined by $T\left(h_{0}, h_{1}, h_{2}, h_{3}\right)=\left(K\left(h_{1}\right), h_{2}, h_{3}, h_{3}\right)$. Clearly,

$$
\mathrm{D}\left(T^{k}\right)= \begin{cases}\mathrm{H} \times \mathrm{D}(K) \times \mathrm{H} \times \mathrm{H} & \text { if } k=1, \\ \mathrm{H} \times \mathrm{D}(K) \times \mathrm{D}(K) \times \mathrm{H} & \text { if } k=2, \\ \mathrm{H} \times \mathrm{D}(K) \times \mathrm{D}(K) \times \mathrm{D}(K) & \text { if } k \geq 3\end{cases}
$$

is closed. Hence $\operatorname{do}(T)=3$. It is not difficult to see that

$$
\operatorname{Im}\left(T_{\lambda}\right)+\mathrm{D}\left(T^{3}\right)= \begin{cases}\mathbf{H} \times \mathbf{H} \times \mathbf{H} \times \mathbf{D}(K) & \text { if } \lambda=1, \\ \mathbf{H} \times \mathbf{H} \times \mathbf{H} \times \mathbf{H} & \text { if } \lambda \neq 1\end{cases}
$$

is closed. Since $T \in \varphi(\mathcal{H})$, it follows that $T \in \Gamma(\mathcal{H})$.

(ii) Let $\mathrm{H}$ be a separable Hilbert space and $\left\{e_{n}: n \in \mathbb{N}\right\}$ be an orthonormal basis of $\mathrm{H}$. Define the following operators $T$ and $L$ on $\mathrm{H}$ by

$\mathrm{D}(T)=\mathrm{D}(L)=\left\langle e_{n}: n \geq 2\right\rangle, \quad T\left(e_{n}\right)=e_{n+1} \quad$ and $\quad L\left(e_{n}\right)=e_{n-1}, \quad \forall n \geq 2$.

It is clear that $\mathrm{D}\left(T^{k}\right)=\mathrm{D}(T)$ and $\mathrm{D}\left(L^{k}\right)=\left\langle e_{n}: n \geq 1+k\right\rangle$, for all $k \geq 1$ and hence $\operatorname{do}(T)=1$ and $\operatorname{do}(L)=+\infty(L \notin \Gamma(\mathrm{H}))$. Since $T \in \varphi(\mathrm{H}), \operatorname{Im}\left(T_{\lambda}\right) \subseteq \mathrm{D}(T)$ for all $\lambda \in \mathbb{C}$ and $\mathrm{D}(T)$ is closed, then $T \in \Gamma(\mathrm{H})$.

The following proposition generalizes [7, Proposition 3.3.2].

Proposition 4.3. Let $T \in \varphi(\mathrm{H})$ and $k \in \mathbb{N}$ such that $\operatorname{ker}\left(T^{k}\right)$ is closed. If $T \in k-q \Phi(\mathrm{H})$, then

$$
\operatorname{Im}\left(T^{i}\right)+\operatorname{ker}\left(T^{k+j}\right) \quad \text { is closed, for all } i+j \geq q_{k}(T) .
$$

Proof. If $T \in k-q \Phi(\mathrm{H})$, then from Proposition 2.11, $\widetilde{T}_{k} \in q \Phi\left(q_{k}(T)\right)\left(\mathrm{H} / \operatorname{ker}\left(T^{k}\right)\right)$. But by [7, Proposition 3.3.2], we have

$$
\operatorname{Im}\left[\left(\widetilde{T_{k}}\right)^{i}\right]+\operatorname{ker}\left[\left(\widetilde{T_{k}}\right)^{j}\right]=\left[\operatorname{Im}\left(T^{i}\right)+\operatorname{ker}\left(T^{k+j}\right)\right] / \operatorname{ker}\left(T^{k}\right) \quad \text { is closed, } \quad \forall i+j \geq q_{k}(T) .
$$


Therefore

$$
\operatorname{Im}\left(T^{i}\right)+\operatorname{ker}\left(T^{k+j}\right) \quad \text { is closed, } \quad \forall i+j \geq q_{k}(T) .
$$

and the proof of the proposition is complete.

For $T \in \varphi(\mathrm{H})$ and $\mathrm{M}$ a subspace of $\mathrm{H}$, we define $T_{\mid \mathrm{M}}$ as the restriction of $T$ to $\mathrm{M}$ viewed as a map from $\mathrm{M}$ onto $\mathrm{M}$.

The next lemma is used in order to show Lemmas 4.5 and 4.8 .

Lemma 4.4. Let $T$ be a paracomplete operator on $\mathrm{H}$ and $P$ be a non-constant complex polynomial. If $q=\mathrm{do}(T)<+\infty$ and $\mathrm{D}\left(T^{q}\right)$ is closed, then

(i) $T_{\mid \mathrm{D}\left(T^{q}\right)}$ is a bounded operator,

(ii) $\operatorname{ker}[P(T)]=\operatorname{ker}\left[P\left(T_{\mid \mathrm{D}\left(T^{q}\right)}\right)\right]$ is closed,

(iii) $\operatorname{lm}\left([P(T)]^{n}\right) \subseteq \mathrm{D}\left(T^{q}\right)$, for all $n \geq q$.

Proof. $(i)$ Let $\widehat{T}$ (resp. $T_{\mid \mathrm{D}\left(T^{q}\right)}$ ) be the restriction of $T$ to $\mathrm{D}\left(T^{q}\right)$ viewed as map from $\mathrm{D}\left(T^{q}\right)$ onto $\mathrm{H}$ (resp. $\mathrm{D}\left(T^{q}\right)$ onto $\mathrm{D}\left(T^{q}\right)$ ). From [7, Proposition 2.1.4, Proposition 2.1.5], it follows that $\widehat{T}$ is a bounded operator. Since for all $x \in \mathrm{D}\left(T^{q}\right)$, we have $\|T x\|=\|\widehat{T} x\| \leq$ $\|\widehat{T}\|\|x\|$, then $T_{\mid \mathrm{D}\left(T^{q}\right)}$ is also a bounded operator.

(ii) Since $\operatorname{ker}[P(T)] \subseteq \mathrm{D}\left([P(T)]^{q}\right)=\mathrm{D}\left(T^{q}\right)$, then $\operatorname{ker}[P(T)]=\operatorname{ker}\left[P\left(T_{\mid \mathrm{D}\left(T^{q}\right)}\right)\right]$ is closed.

(iii) Let $y \in \operatorname{Im}\left([P(T)]^{n}\right)$, then there exists $x \in \mathrm{D}\left([P(T)]^{n}\right)=\mathrm{D}\left(T^{q}\right)=\mathrm{D}\left([P(T)]^{n+q}\right)$ such that $y=[P(T)]^{n} x$ i.e., $y \in \mathrm{D}\left(T^{q}\right)$. This completes the proof.

Lemma 4.5. Let $T \in \varphi(\mathrm{H}), m \in \mathbb{N} \backslash\{0\}$ and $k \in \mathbb{N}$.

(i) If $q=\mathrm{do}(T)<+\infty$ and $\mathrm{D}\left(T^{q}\right)$ is closed, then

$$
T \in k-q \Phi(\mathrm{H}) \Longrightarrow T^{m} \in k-q \Phi(\mathrm{H})
$$

(ii) If $T \in \Gamma(\mathrm{H})$, then

$$
T^{m} \in k-q \Phi(\mathrm{H}) \Longrightarrow T \in p q \Phi(\mathrm{H}) \text {. }
$$

Proof. $(i)$ Let $n \in \mathbb{N} \backslash\{0\}$ and $d=q_{k}(T)$. Since $d+k \geq q_{0}(T)$ (see Lemma 2.1), it follows from [7, Proposition 3.1.1] that

$$
\operatorname{ker}\left[\left(T^{n}\right)^{j}\right] \subseteq \operatorname{Im}\left(T^{n}\right)+\operatorname{ker}\left(T^{d+k}\right) \subseteq \operatorname{Im}\left(T^{n}\right)+\operatorname{ker}\left[\left(T^{n}\right)^{(d+k)}\right], \quad \forall j \in \mathbb{N},
$$

and so $q_{0}\left(T^{n}\right) \leq d+k$. Hence, by Lemma 2.1 , we obtain $q_{k}\left(T^{n}\right) \leq d$. In the other hand, from Lemma 4.4, we have $\operatorname{ker}\left(T^{j}\right)$ is closed for all $j \in \mathbb{N}$ and by Proposition 4.3, we know that $\operatorname{Im}\left(T^{n d}\right)+\operatorname{ker}\left(T^{n k}\right)$ and $\operatorname{Im}\left(T^{n}\right)+\operatorname{ker}\left(T^{n(d+k)}\right)$ are closed, this proves that $\left[\operatorname{lm}\left(T^{n d}\right)+\operatorname{ker}\left(T^{n k}\right)\right] \cap \operatorname{ker}\left(T^{n(k+1)}\right)$ is closed. Since $d_{n}=q_{k}\left(T^{n}\right) \leq d$, then

$$
\left(\operatorname{Im}\left[\left(T^{n}\right)^{d_{n}}\right]+\operatorname{ker}\left[\left(T^{n}\right)^{k}\right]\right) \cap \operatorname{ker}\left[\left(T^{n}\right)^{k+1}\right]=\left(\operatorname{Im}\left[\left(T^{n}\right)^{d}\right]+\operatorname{ker}\left[\left(T^{n}\right)^{k}\right]\right) \cap \operatorname{ker}\left[\left(T^{n}\right)^{k+1}\right]
$$

and

$$
\operatorname{Im}\left(T^{n}\right)+\operatorname{ker}\left(T^{n\left(d_{n}+k\right)}\right)=\operatorname{Im}\left(T^{n}\right)+\operatorname{ker}\left(T^{n(d+k)}\right)
$$

are closed. It follows now from Corollary 2.12, that $T^{n} \in k-q \Phi(\mathrm{H})$.

(ii) Let $l \in \mathbb{N}$ such that $l m>\operatorname{do}(T)$, then by $(i), T^{n} \in k-q \Phi(\mathrm{H})$, with $n=l m$. Let $d=q_{k}\left(T^{n}\right)=\max \left\{q_{0}\left(T^{n}\right)-k, 0\right\}$, then $d+k \geq q_{0}\left(T^{n}\right)$. For all $j \in \mathbb{N}$, by [7, Proposition 3.1.1], we see that

$$
\operatorname{ker}\left(T^{j}\right) \subseteq \operatorname{ker}\left[\left(T^{n}\right)^{j}\right] \subseteq \operatorname{Im}\left(T^{n}\right)+\operatorname{ker}\left(T^{n(d+k)}\right) \subseteq \operatorname{Im}(T)+\operatorname{ker}\left(T^{n(d+k)}\right)
$$

and hence $q_{0}(T) \leq n(d+k)$. Let $\alpha=k n+n d-d \geq k$ and $d_{\alpha}=q_{\alpha}(T)$. Now by Lemma 2.1 , we get

$$
d_{\alpha} \leq q_{k}(T)=\max \left\{q_{0}(T)-k, 0\right\} \leq n(d+k)-k .
$$


Therefore

$$
\operatorname{Im}(T)+\operatorname{ker}\left(T^{d_{\alpha}+\alpha}\right)=\operatorname{Im}(T)+\operatorname{ker}\left(T^{q_{k}(T)+\alpha}\right)=\operatorname{Im}(T)+\operatorname{ker}\left(T^{q_{k}(T)+k}\right) .
$$

Since $q_{k}(T)+k \leq n(d+k) \leq n(d+k)+n-1$, we deduce

$$
\operatorname{Im}(T)+\operatorname{ker}\left(T^{d_{\alpha}+\alpha}\right)=\operatorname{Im}(T)+\operatorname{ker}\left(T^{n(d+k)+n-1}\right) .
$$

But $n>\operatorname{do}(T)$, then $\mathrm{D}\left(T^{n-1}\right)=\mathrm{D}\left(T^{q}\right)$ and $\operatorname{Im}\left(T^{n}\right) \subseteq \mathrm{D}\left(T^{q}\right)$. We have by Lemma 4.4 that $S=T_{\mid \mathrm{D}\left(T^{q}\right)}$ is a bounded operator, so that

$$
\begin{aligned}
{\left[\operatorname{Im}(T)+\operatorname{ker}\left(T^{d_{\alpha}+\alpha}\right)\right] \cap \mathrm{D}\left(T^{q}\right) } & =\left[\operatorname{Im}(T)+\operatorname{ker}\left(T^{n(d+k)+n-1}\right)\right] \cap \mathrm{D}\left(T^{n-1}\right) \\
& =T^{-(n-1)}\left(\operatorname{Im}\left(T^{n}\right)+\operatorname{ker}\left(T^{n(d+k)}\right)\right) \\
& =S^{-(n-1)}\left(\operatorname{Im}\left(T^{n}\right)+\operatorname{ker}\left(T^{n(d+k)}\right)\right)
\end{aligned}
$$

is closed. As $\left[\operatorname{Im}(T)+\operatorname{ker}\left(T^{d_{\alpha}+\alpha}\right)\right]+\mathrm{D}\left(T^{q}\right)=\operatorname{Im}(T)+\mathrm{D}\left(T^{q}\right)$ is closed, we infer by [7, Proposition 2.1.1] and Lemma 2.9 that $\operatorname{Im}(T)+\operatorname{ker}\left(T^{d_{\alpha}+\alpha}\right)$ is closed. In the other hand, from Proposition 4.3, for all $i \geq d$ the subspace $\operatorname{Im}\left(T^{n i}\right)+\operatorname{ker}\left(T^{k n}\right)$ is closed. Suppose that $i \geq \max \{2 d+k, 1\}$, since $\operatorname{Im}\left(T^{n i-(n d-d)}\right)+\operatorname{ker}\left(T^{\alpha}\right) \subseteq \mathrm{D}\left(T^{q}\right)=\mathrm{D}\left(T^{(n d-d)}\right)$ and $\operatorname{Im}\left(T^{n i}\right)+\operatorname{ker}\left(T^{k n}\right) \subseteq \mathrm{D}\left(T^{q}\right)$ (see Lemma 4.4), then

$$
\begin{aligned}
\operatorname{Im}\left(T^{n i-(n d-d)}\right)+\operatorname{ker}\left(T^{\alpha}\right) & =\left[\operatorname{Im}\left(T^{n i-(n d-d)}\right)+\operatorname{ker}\left(T^{\alpha}\right)\right] \cap \mathrm{D}\left(T^{(n d-d)}\right) \\
& =T^{-(n d-d)}\left(\operatorname{Im}\left(T^{n i}\right)+\operatorname{ker}\left(T^{n k}\right)\right) \\
& =S^{-(n d-d)}\left(\operatorname{Im}\left(T^{n i}\right)+\operatorname{ker}\left(T^{n k}\right)\right)
\end{aligned}
$$

is closed. This implies that $\mathbf{Z}=\left[\operatorname{Im}\left(T^{n i-(n d-d)}\right)+\operatorname{ker}\left(T^{\alpha}\right)\right] \cap \operatorname{ker}\left(T^{\alpha+1}\right)$ is closed. We have

$$
n i-(n d-d)=n(i-d)+d \geq n(d+k)+d \geq n(d+k) \geq q_{k}(T) \geq d_{\alpha},
$$

thus $\mathbf{Z}=\left[\operatorname{Im}\left(T^{d_{\alpha}}\right)+\operatorname{ker}\left(T^{\alpha}\right)\right] \cap \operatorname{ker}\left(T^{\alpha+1}\right)$ is closed. Hence by Corollary 2.12, it follows that $T \in \alpha-q \Phi\left(d_{\alpha}\right)(\mathrm{H})$. This completes the proof.

As an immediate consequence of Proposition 2.7 and Lemma 4.5, we obtain the following result.

Corollary 4.6. Let $T \in \mathscr{B}(\mathrm{H})$. The following conditions are equivalent :

(i) $T$ has topological uniform descent;

(ii) $T^{n}$ has topological uniform descent for all $n \in \mathbb{N}$;

(iii) $T^{n}$ has topological uniform descent for some $n \in \mathbb{N}$.

The next lemma is used to prove Lemma 4.8.

Lemma 4.7. Let $k \in \mathbb{N}$ and $T \in \varphi(\mathrm{H})$ such that $\operatorname{ker}\left(T^{n}\right)$ is closed for all $n \in \mathbb{N}$. If $T \in k-q \Phi(\mathrm{H})$, then $T \in(k+1)-q \Phi(\mathrm{H})$.

Proof. Let $T \in k-q \Phi(\mathrm{H})$, from Lemma 2.1, $d=q_{k+1}(T) \leq q_{k}(T)<+\infty$ and hence

$$
\left[\operatorname{Im}\left(T^{d}\right)+\operatorname{ker}\left(T^{k+1}\right)\right] \cap \operatorname{ker}\left(T^{k+2}\right)=\left[\operatorname{Im}\left(T^{d+q_{k}(T)}\right)+\operatorname{ker}\left(T^{k+1}\right)\right] \cap \operatorname{ker}\left(T^{k+2}\right)
$$

and

$$
\operatorname{Im}(T)+\operatorname{ker}\left(T^{d+k+1}\right)=\operatorname{Im}(T)+\operatorname{ker}\left(T^{q_{k}(T)+k+1}\right)=\operatorname{Im}(T)+\operatorname{ker}\left(T^{q_{k}(T)+k}\right) .
$$

Since by Proposition 4.3, we know that $\operatorname{Im}\left(T^{d+q_{k}(T)}\right)+\operatorname{ker}\left(T^{k+1}\right)$ is closed, then it follows from (1) and (2) that $T \in(k+1)-q \Phi(\mathrm{H})$, and this completes the proof.

The next lemma is used to prove Corollary 4.10.

Lemma 4.8. Let $T: \mathrm{D}(T) \subseteq \mathrm{H} \longrightarrow \mathrm{H}$ be a paracomplete operator. Let $A=P(T)$, $B=Q(T)$, where $P$ and $Q$ are relatively prime polynomials, and $k \in \mathbb{N}$. 
(i) $q_{k}\left(A^{n} B^{n}\right)=\max \left\{q_{k}\left(A^{n}\right), q_{k}\left(B^{n}\right)\right\}$, for all $n \in \mathbb{N}$.

(ii) If $q=\operatorname{do}(T)<+\infty$ and $\mathrm{D}\left(T^{q}\right)$ is closed, then

$$
A, B \in k-q \Phi(\mathrm{H}) \Longrightarrow A B \in k-q \Phi(\mathrm{H}) .
$$

(iii) If $T \in \Gamma(\mathrm{H})$, then

$$
A, B \in p q \Phi(\mathrm{H}) \Longleftrightarrow A B \in p q \Phi(\mathrm{H}) .
$$

Proof. (i) For $n, k \in \mathbb{N}$, we denote by $Z_{n}^{k}(T)=\left[\operatorname{Im}\left(T^{n}\right)+\operatorname{ker}\left(T^{k}\right)\right] \cap \operatorname{ker}\left(T^{k+1}\right)$. By $[4$, Lemma 4.4], we see

$$
\begin{aligned}
Z_{n}^{k}(A B) & =\left[\operatorname{Im}\left(A^{n} B^{n}\right)+\operatorname{ker}\left(A^{k} B^{k}\right)\right] \cap \operatorname{ker}\left(A^{k+1} B^{k+1}\right) \\
& =\left[\operatorname{Im}\left(A^{n}\right) \cap \operatorname{Im}\left(B^{n}\right)+\operatorname{ker}\left(A^{k}\right)+\operatorname{ker}\left(B^{k}\right)\right] \cap\left[\operatorname{ker}\left(A^{k+1}\right)+\operatorname{ker}\left(B^{k+1}\right)\right] \\
& =\left[\left[\operatorname{Im}\left(A^{n}\right)+\operatorname{ker}\left(A^{k}\right)\right] \cap \operatorname{Im}\left(B^{n}\right)+\operatorname{ker}\left(B^{k}\right)\right] \cap\left[\operatorname{ker}\left(A^{k+1}\right)+\operatorname{ker}\left(B^{k+1}\right)\right] \\
& =\left[\operatorname{Im}\left(A^{n}\right)+\operatorname{ker}\left(A^{k}\right)\right] \cap\left[\operatorname{Im}\left(B^{n}\right)+\operatorname{ker}\left(B^{k}\right)\right] \cap\left[\operatorname{ker}\left(A^{k+1}\right)+\operatorname{ker}\left(B^{k+1}\right)\right] \\
& =\left[\operatorname{lm}\left(A^{n}\right)+\operatorname{ker}\left(A^{k}\right)\right] \cap\left[\operatorname{ker}\left(A^{k+1}\right)+\left(\operatorname{Im}\left(B^{n}\right)+\operatorname{ker}\left(B^{k}\right)\right) \cap \operatorname{ker}\left(B^{k+1}\right)\right] \\
& =\left[\operatorname{Im}\left(A^{n}\right)+\operatorname{ker}\left(A^{k}\right)\right] \cap \operatorname{ker}\left(A^{k+1}\right)+\left[\operatorname{Im}\left(B^{n}\right)+\operatorname{ker}\left(B^{k}\right)\right] \cap \operatorname{ker}\left(B^{k+1}\right) \\
& =Z_{n}^{k}(A)+Z_{n}^{k}(B)
\end{aligned}
$$

and

Therefore

$$
Z_{n}^{k}(A) \cap Z_{n}^{k}(B) \subseteq \operatorname{ker}\left(A^{k+1}\right) \cap \operatorname{ker}\left(B^{k+1}\right)=\{0\} .
$$

$$
q_{k}\left(A^{n} B^{n}\right)=\max \left\{q_{k}\left(A^{n}\right), q_{k}\left(B^{n}\right)\right\}, \quad \forall n \in \mathbb{N} .
$$

(ii) First, recall that from Lemma 4.4, we get $\operatorname{ker}\left(A^{k}\right)$ and $\operatorname{ker}\left(B^{k}\right)$ are closed, for all $k \in \mathbb{N}$. For $j, n \in \mathbb{N}$, we have

$$
\begin{aligned}
\operatorname{Im}\left(A^{n} B^{n}\right)+\operatorname{ker}\left(A^{j} B^{j}\right) & =\operatorname{Im}\left(A^{n}\right) \cap \operatorname{Im}\left(B^{n}\right)+\operatorname{ker}\left(A^{j}\right)+\operatorname{ker}\left(B^{j}\right) \\
& =\left[\operatorname{Im}\left(A^{n}\right)+\operatorname{ker}\left(A^{j}\right)\right] \cap\left[\operatorname{Im}\left(B^{n}\right)+\operatorname{ker}\left(B^{j}\right)\right] .
\end{aligned}
$$

Assume that $A, B \in k-q \Phi(\mathrm{H})$ and let $d=q_{k}(A B)=\max \left\{q_{k}(A), q_{k}(B)\right\}$. In particular, this allows us to see

$$
\operatorname{Im}(A)+\operatorname{ker}\left(A^{k+d}\right) \quad \text { and } \operatorname{Im}(B)+\operatorname{ker}\left(B^{k+d}\right) \quad \text { are closed. }
$$

Furthermore, from Proposition 4.3, it follows that

$$
\operatorname{Im}\left(A^{d}\right)+\operatorname{ker}\left(A^{k}\right) \quad \text { and } \quad \operatorname{Im}\left(B^{d}\right)+\operatorname{ker}\left(B^{k}\right) \quad \text { are closed. }
$$

Thus, taking into account of the equalities (1), (2), (3) and Corollary 2.12, we deduce that $A B \in k-q \Phi(\mathrm{H})$.

(iii) Taking into account of [7, Proposition 2.1.3] and Lemma 2.9, we obtain that $Z_{n}^{k}(A)$ (resp. $Z_{n}^{k}(B)$ ) is paracomplete and applying [7, Proposition 2.1.1], we conclude that

$$
Z_{n}^{k}(A B) \quad \text { is closed } \Longrightarrow Z_{n}^{k}(A) \quad \text { and } \quad Z_{n}^{k}(B) \text { are closed. }
$$

Since for $j \in \mathbb{N}$ and $n \geq \operatorname{do}(T)$, we have

$$
\left[\operatorname{Im}\left(A^{n}\right)+\operatorname{ker}\left(A^{j}\right)\right]+\left[\operatorname{Im}\left(B^{n}\right)+\operatorname{ker}\left(B^{j}\right)\right]=\operatorname{Im}\left(A^{n}\right)+\operatorname{Im}\left(B^{n}\right)=\mathrm{D}\left(T^{q}\right),
$$

it follows from [7, Proposition 2.1.1, Proposition 2.1.3], Lemma 2.9 and (1) that (5)

$\operatorname{Im}\left(A^{n} B^{n}\right)+\operatorname{ker}\left(A^{j} B^{j}\right) \quad$ is closed $\Longleftrightarrow\left\{\begin{array}{l}\operatorname{Im}\left(A^{n}\right)+\operatorname{ker}\left(A^{j}\right), \\ \operatorname{Im}\left(B^{n}\right)+\operatorname{ker}\left(B^{j}\right)\end{array}\right.$ are closed, $\forall n \geq \operatorname{do}(T)$.

Assume that $A B \in k-q \Phi(\mathrm{H})$, then $A^{n} B^{n} \in k-q \Phi(\mathrm{H})$, for $n \geq \operatorname{do}(T)$ according to Lemma 4.5. In particular $Z_{d}^{k}\left(A^{n} B^{n}\right)$ and $\operatorname{Im}\left(B^{n} A^{n}\right)+\operatorname{ker}\left[\left(A^{n} B^{n}\right)^{k+d}\right]$ are closed, with $d=q_{k}\left(A^{n} B^{n}\right)$. Since $q_{k}\left(A^{n}\right) \leq d$, taking into account of (4) and (5), we deduce that $Z_{q_{k}\left(A^{n}\right)}^{k}\left(A^{n}\right)=Z_{d}^{k}\left(A^{n}\right)$ and $\operatorname{Im}\left(A^{n}\right)+\operatorname{ker}\left[\left(A^{n}\right)^{k+q_{k}\left(A^{n}\right)}\right]=\operatorname{Im}\left(A^{n}\right)+\operatorname{ker}\left[\left(A^{n}\right)^{k+d}\right]$ are closed. Therefore by Corollary 2.12, we obtain that $A^{n} \in k-q \Phi(\mathrm{H})$ and hence $A \in p q \Phi(\mathrm{H})$ according to Lemma 4.5. Consequently if $A B \in p q \Phi(\mathrm{H})$, then $A, B \in p q \Phi(\mathrm{H})$. 
Suppose, conversely, that $A, B \in p q \Phi(\mathrm{H})$, then there exists $k_{1}, k_{2} \in \mathbb{N}$ such that $A \in k_{1}-q \Phi(\mathrm{H})$ and $B \in k_{2}-q \Phi(\mathrm{H})$. Now from Lemma 4.7, it follows that $A, B \in k-q \Phi(\mathrm{H})$, with $k=\max \left\{k_{1}, k_{2}\right\}$. Finally, by $(i i)$, we obtain $A B \in p q \Phi(\mathrm{H})$. This completes the proof.

Using Proposition 2.7, [10, Lemma 12.8] and the proof of Lemma 4.8, one proves the following result.

Corollary 4.9. Let $T, S, L, R \in \mathscr{B}(\mathrm{H})$ be mutually commuting operators, satisfying $T R+L S=I$. Then $T$ has topological uniform descent if and only if the same holds for $S$.

Corollary 4.10. Let $T \in \varphi(\mathrm{H})$ and $P(Z)=\left(\lambda_{1}-Z\right)^{m_{1}}\left(\lambda_{2}-Z\right)^{m_{2}} \cdots\left(\lambda_{s}-Z\right)^{m_{s}}$ be a complex polynomial such that $m_{i} \neq 0$ for all $i=1,2, \ldots, s$.

(i) Let $k \in \mathbb{N}$, if $q=\mathrm{do}(T)<+\infty$ and $\mathrm{D}\left(T^{q}\right)$ is closed, then

$$
\forall 1 \leq i \leq s, \quad \lambda_{i} \in \varrho_{q \Phi}^{k}(T) \Longrightarrow 0 \in \varrho_{q \Phi}^{k}(P(T)) .
$$

(ii) If $T \in \Gamma(\mathrm{H})$, then

$$
0 \in \varrho_{q \Phi}^{\infty}(P(T)) \Longleftrightarrow \lambda_{i} \in \varrho_{q \Phi}^{\infty}(T), \quad \forall 1 \leq i \leq s .
$$

Proof. From Lemmas 4.5 and 4.8, it follows that

$$
\begin{aligned}
\forall 1 \leq i \leq s, \quad \lambda_{i} \in \varrho_{q \Phi}^{k}(T) & \Longrightarrow 0 \in \bigcap_{1 \leq i \leq s} \varrho_{q \Phi}^{k}\left(\lambda_{i} I-T\right) \\
& \Longrightarrow 0 \in \bigcap_{1 \leq i \leq s} \varrho_{q \Phi}^{k}\left[\left(\lambda_{i} I-T\right)^{m_{i}}\right] \\
& \Longrightarrow 0 \in \varrho_{q \Phi}^{k}(P(T))
\end{aligned}
$$

and

$$
\begin{aligned}
0 \in \varrho_{q \Phi}^{\infty}(P(T)) & \Longleftrightarrow 0 \in \bigcap_{1 \leq i \leq s} \varrho_{q \Phi}^{\infty}\left[\left(\lambda_{i} I-T\right)^{m_{i}}\right] \\
& \Longleftrightarrow 0 \in \bigcap_{1 \leq i \leq s}^{\infty} \varrho_{q \Phi}^{\infty}\left(\lambda_{i} I-T\right) \\
& \Longleftrightarrow \lambda_{i} \in \varrho_{q \Phi}^{\infty}(T), \quad \forall 1 \leq i \leq s .
\end{aligned}
$$

This completes the proof.

Corollary 4.11. Let $T \in \mathscr{B}(\mathrm{H})$ and $P(Z)=\left(\lambda_{1}-Z\right)^{m_{1}}\left(\lambda_{2}-Z\right)^{m_{2}} \cdots\left(\lambda_{s}-Z\right)^{m_{s}}$ be a complex polynomial such that $m_{i} \neq 0$ for all $i=1,2, \ldots, s$. The following conditions are equivalent :

(i) $P(T)$ has topological uniform descent;

(ii) $\lambda_{i} I-T$ has topological uniform descent for all $1 \leq i \leq s$.

Now we give a spectral mapping theorem which is our main result.

Theorem 4.12. Let $T \in \varphi(\mathrm{H})$ and $P$ be a non-constant complex polynomial.

(i) If $k \in \mathbb{N}, q=\mathrm{do}(T)<+\infty$ and $\mathrm{D}\left(T^{q}\right)$ is closed, then

$$
\sigma_{q \Phi}^{k}(P(T)) \subseteq P\left(\sigma_{q \Phi}^{k}(T)\right) .
$$

(ii) If $T \in \Gamma(\mathrm{H})$, then

$$
P\left(\sigma_{q \Phi}^{\infty}(T)\right)=\sigma_{q \Phi}^{\infty}(P(T)) .
$$

In particular, the topological uniform descent spectrum of a bounded operator on a Hilbert space satisfies the non-constant polynomial version of the spectral mapping theorem. 
Proof. (i) Let $\lambda \in \sigma_{q \Phi}^{k}(P(T))$ and suppose that $\lambda-P(Z)=\left(\mu_{1}-Z\right)^{m_{1}} \cdots\left(\mu_{s}-Z\right)^{m_{s}}$. From Corollary 4.10, it follows that there exists $i \in\{1,2, \ldots, s\}$ such that $\mu_{i} \in \sigma_{q \Phi}^{k}(T)$. Hence $\lambda=P\left(\mu_{i}\right) \in P\left(\sigma_{q \Phi}^{k}(T)\right)$.

(ii) From Corollary 4.10, it follows that

$$
\begin{aligned}
\lambda \in P\left(\sigma_{q \Phi}^{\infty}(T)\right) & \Longleftrightarrow \lambda=P(\mu), \text { with } \mu \in \sigma_{q \Phi}^{\infty}(T), \\
& \Longleftrightarrow \lambda-P(Z)=(\mu-Z)^{k} Q(Z), \text { with } Q(\mu) \neq 0, \\
& \Longleftrightarrow \lambda \in \sigma_{q \Phi}^{\infty}(P(T)),
\end{aligned}
$$

which completes the proof.

Question 1. Let $T \in \Gamma(\mathrm{H}), k \in \mathbb{N}$ and $P$ be a non-constant complex polynomial. It is not clear at present whether $P\left(\sigma_{q \Phi}^{k}(T)\right)=\sigma_{q \Phi}^{k}(P(T))$ ?

Corollary 4.13. Let $T \in \varphi(\mathrm{H})$ such that $q=\operatorname{do}(T)<+\infty$ and $\mathrm{D}\left(T^{q}\right)$ is closed, and $P$ be a complex polynomial having no roots in $\sigma_{q \Phi}^{k}(T)$, for $k \in \mathbb{N}$, then $P(T)$ is a $k$-quasiFredholm operator.

Corollary 4.14. Let $T \in \Gamma(\mathrm{H})$ and $P$ be a complex polynomial having no roots in $\sigma_{q \Phi}^{\infty}(T)$, then $P(T)$ is pseudo-quasi-Fredholm. Furthermore, $P(T)$ has topological uniform descent, when $T \in \mathscr{B}(\mathrm{H})$.

The next lemma is used to prove Theorem 4.16.

Lemma 4.15. Let $T, L \in \mathscr{B}(\mathrm{H})$ such that $T L=L T$. If $L$ is invertible, then for all $k \in \mathbb{N}$, we have $T \in k-q \Phi(\mathrm{H})$ if and only if $T L \in k-q \Phi(\mathrm{H})$.

Proof. For $n \in \mathbb{N}$, we know that $\operatorname{ker}\left(T^{n}\right)=\operatorname{ker}\left(T^{n} L^{n}\right)$ and $\operatorname{Im}\left(T^{n}\right)=\operatorname{Im}\left(T^{n} L^{n}\right)$. For every $k, n, i \in \mathbb{N}$, we deduce that $q_{k}(T)=q_{k}(T L), \operatorname{Im}\left(T^{i}\right)+\operatorname{ker}\left(T^{n}\right)$ is closed if and only if $\operatorname{Im}\left(L^{i} T^{i}\right)+\operatorname{ker}\left(L^{n} T^{n}\right)$ is closed and $\left[\operatorname{Im}\left(T^{i}\right)+\operatorname{ker}\left(T^{k}\right)\right] \cap \operatorname{ker}\left(T^{k+1}\right)$ is closed if and only if $\left[\operatorname{Im}\left(L^{i} T^{i}\right)+\operatorname{ker}\left(L^{k} T^{k}\right)\right] \cap \operatorname{ker}\left(L^{k+1} T^{k+1}\right)$ is closed. Therefore,

$$
T \in k-q \Phi(\mathrm{H}) \Longleftrightarrow T L \in k-q \Phi(\mathrm{H}) .
$$

This completes the proof.

The spectral mapping theorem holds for the pseudo-quasi-Fredholm spectrum.

Theorem 4.16. Let $T \in \mathscr{B}(\mathrm{H})$ and $f$ be an analytic function in a neighborhood of the usual spectrum $\sigma(T)$ and not locally constant in $\sigma(T)$. For $k \in \mathbb{N}$, we have

$$
\sigma_{q \Phi}^{k}(f(T)) \subseteq f\left(\sigma_{q \Phi}^{k}(T)\right) \quad \text { and } \quad f\left(\sigma_{q \Phi}^{\infty}(T)\right)=\sigma_{q \Phi}^{\infty}(f(T)) .
$$

So, the topological uniform descent spectrum of a bounded operator on a Hilbert space satisfies the spectral mapping theorem.

Proof. Let $\mu \in \mathbb{C}$ and $f$ be an analytic function in a neighborhood of $\sigma(T)$. Since $\sigma(T)$ is a compact subset of $\mathbb{C}$, the function $f(z)-f(\mu)$ possesses at most a finite number of zeros in $\sigma(T)$. So

$$
f(z)-f(\mu)=(z-\mu)^{m_{0}}\left(z-\lambda_{1}\right)^{m_{1}} \cdots\left(z-\lambda_{n}\right)^{m_{n}} g(z),
$$

where $g(z)$ is a non-vanishing analytic function on $\sigma(T)$. Using the functional calculus we deduce that:

$$
f(T)-f(\mu) I=(T-\mu I)^{m_{0}}\left(T-\lambda_{1} I\right)^{m_{1}} \cdots\left(T-\lambda_{n} I\right)^{m_{n}} g(T),
$$

where $g(T)$ is an invertible operator. Therefore

$$
[f(T)-f(\mu) I]\left(g(T)^{-1}\right)=(T-\mu I)^{m_{0}}\left(T-\lambda_{1} I\right)^{m_{1}} \cdots\left(T-\lambda_{n} I\right)^{m_{n}} .
$$


So from Corollary 4.10 and Lemma 4.15, it follows that

$$
\begin{aligned}
\mu \in \sigma_{q \Phi}^{\infty}(T) & \Longleftrightarrow[f(T)-f(\mu) I]\left(g(T)^{-1}\right) \notin p q \Phi(\mathrm{H}) \\
& \Longleftrightarrow f(T)-f(\mu) I \notin p q \Phi(\mathrm{H}) \\
& \Longleftrightarrow f(\mu) \in \sigma_{q \Phi}^{\infty}(f(T)) .
\end{aligned}
$$

In the same way, we obtain that

$$
\sigma_{q \Phi}^{k}(f(T)) \subseteq f\left(\sigma_{q \Phi}^{k}(T)\right) .
$$

This proves the theorem.

Corollary 4.17. Let $T \in \mathscr{B}(\mathrm{H})$ and $f$ be an analytic function in a neighborhood of the usual spectrum $\sigma(T)$ having no roots in $\sigma_{q \Phi}^{\infty}(T)$ (resp. $\sigma_{q \Phi}^{k}(T)$, for $k \in \mathbb{N}$ ) and not locally constant in $\sigma(T)$. Then $f(T)$ is a pseudo-quasi-Fredholm (resp. k-quasi-Fredholm) operator.

Remark 4.18. Recall that if $T \in \varphi(\mathrm{H})$ such that $\varrho_{e}^{+}(T) \neq \emptyset$, then $\operatorname{ker}(P(T))$ is closed, for all complex polynomial $P$. Thus, the first assertion of Lemma 4.5 and the second assertion of Lemma 4.8 are true also for a closed operator $T$ on a Hilbert space such that $\varrho_{e}^{+}(T) \neq \emptyset$ and not necessarily $q=\operatorname{do}(T)<+\infty$ and $\mathrm{D}\left(T^{q}\right)$ is closed. Hence, we can prove that all results in Section 4 related to the k-quasi-Fredholm spectrum remain valid for an operator $T \in \varphi(\mathrm{H})$ such that $\varrho_{e}^{+}(T) \neq \emptyset$ without the assumption that $q=\operatorname{do}(T)<+\infty$ and $\mathrm{D}\left(T^{q}\right)$ is closed.

\section{The K-QUASI-Fredholm AND FINITE-DIMENSIONAL PERTURBATIONS}

For two subspaces $\mathrm{M}$ and $\mathrm{N}$ of $\mathrm{H}$, we write $\mathrm{M} \stackrel{e}{\subset} \mathrm{N}$ if there exists a finite-dimensional subspace $\mathrm{V}$ of $\mathrm{H}$ such that $\mathrm{M} \subset \mathrm{N}+\mathrm{V}$, i.e. $\operatorname{dim} \mathrm{M} /(\mathrm{M} \cap \mathrm{N})=\operatorname{dim}(\mathrm{M}+\mathrm{N}) / \mathrm{N}<+\infty$. Similarly, we write $\mathrm{M} \stackrel{e}{=} \mathrm{N}$ if both $\mathrm{M} \stackrel{e}{\subset} \mathrm{N}$ and $\mathrm{N} \stackrel{e}{\subset} \mathrm{M}$.

The elementary next lemma is used to show Lemma 5.2.

Lemma 5.1. Let $T \in \varphi(\mathrm{H})$ and $F \in \mathscr{B}(\mathrm{H})$ such that $\operatorname{dim} \operatorname{Im}(F)<+\infty, \operatorname{Im}(F) \subset \mathrm{D}(T)$ and $T F x=F T x$, for all $x \in \mathrm{D}(T)$. Then for every $n \in \mathbb{N}$, we have

$$
\operatorname{ker}\left[(T+F)^{n}\right] \stackrel{e}{=} \operatorname{ker}\left(T^{n}\right) \quad \text { and } \quad \operatorname{Im}\left[(T+F)^{n}\right] \stackrel{e}{=} \operatorname{Im}\left(T^{n}\right)
$$

In particular,

$$
\operatorname{ker}\left[(T+F)^{n}\right]+\operatorname{Im}\left[(T+F)^{i}\right] \stackrel{e}{=} \operatorname{ker}\left(T^{n}\right)+\operatorname{Im}\left(T^{i}\right), \quad \forall n, i \in \mathbb{N} .
$$

Proof. For $n \in \mathbb{N}$, we define

$$
\begin{aligned}
\theta: \operatorname{ker}\left[(T+F)^{n}\right] & \longrightarrow \operatorname{Im}(F) \\
x & \longmapsto T^{n} x,
\end{aligned} \quad \text { and } \begin{aligned}
\psi: \operatorname{ker}\left(T^{n}\right) & \longrightarrow \operatorname{Im}(F) \\
x & \longmapsto(T+F)^{n} x .
\end{aligned}
$$

We have

$$
\begin{aligned}
\operatorname{dim} \operatorname{ker}\left[(T+F)^{n}\right] /\left(\operatorname{ker}\left[(T+F)^{n}\right] \cap \operatorname{ker}\left(T^{n}\right)\right) & =\operatorname{dim} \operatorname{ker}\left[(T+F)^{n}\right] / \operatorname{ker}(\theta) \\
& \leq \operatorname{dim} \operatorname{lm}(F)<+\infty
\end{aligned}
$$

and

$$
\begin{aligned}
\operatorname{dim} \operatorname{ker}\left(T^{n}\right) /\left(\operatorname{ker}\left[(T+F)^{n}\right] \cap \operatorname{ker}\left(T^{n}\right)\right) & =\operatorname{dim} \operatorname{ker}\left(T^{n}\right) / \operatorname{ker}(\psi) \\
& \leq \operatorname{dim} \operatorname{Im}(F)<+\infty
\end{aligned}
$$

This implies that

$$
\operatorname{ker}\left[(T+F)^{n}\right] \stackrel{e}{=} \operatorname{ker}\left(T^{n}\right), \quad \forall n \in \mathbb{N} .
$$

Since $(T+F)^{n}-T^{n}$ is a finite dimensional operator, then $\operatorname{Im}\left[(T+F)^{n}\right] \stackrel{e}{=} \operatorname{Im}\left(T^{n}\right)$. This completes the proof. 
Lemma 5.2. Let $T \in \varphi(\mathrm{H})$ and $F \in \mathscr{B}(\mathrm{H})$ such that $\operatorname{dim} \operatorname{Im}(F)<+\infty, \operatorname{Im}(F) \subset \mathrm{D}(T)$ and $T F x=F T x$, for all $x \in \mathrm{D}(T)$. Then

$$
q_{0}(T)<+\infty \Longleftrightarrow q_{0}(T+F)<+\infty .
$$

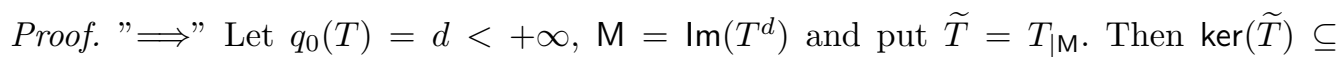
$\operatorname{Im}^{\infty}(\widetilde{T})$ and $\widetilde{T}\left(\operatorname{Im}^{\infty}(T)\right)=\operatorname{Im}^{\infty}(T)$. Indeed, we have

$$
\operatorname{ker}(\widetilde{T})=\operatorname{ker}(T) \cap \operatorname{Im}\left(T^{d}\right)=\operatorname{ker}(T) \cap \operatorname{Im}\left(T^{d+n}\right) \subseteq \operatorname{Im}\left(\widetilde{T}^{n}\right), \quad \forall n \in \mathbb{N}
$$

and so $\operatorname{ker}(\widetilde{T}) \subseteq \operatorname{Im}^{\infty}(\widetilde{T})$. Now let $z \in \operatorname{Im}^{\infty}(T)=\operatorname{Im}^{\infty}(\widetilde{T})$, then there exists $x \in \mathrm{D}(\widetilde{T})$ such that $z=\widetilde{T} x$. Moreover, for every $n \in \mathbb{N}$, there exists $y \in \mathrm{D}\left(\widetilde{T}^{n+1}\right) \subseteq \mathrm{D}\left(\widetilde{T}^{n}\right)$ such that $\widetilde{T}^{n+1} y=\widetilde{T} x$, so $x-\widetilde{T}^{n} y \in \operatorname{ker}(\widetilde{T}) \subseteq \operatorname{Im}^{\infty}(\widetilde{T}) \subseteq \operatorname{Im}\left(\widetilde{T}^{n}\right)$. Therefore $x \in \operatorname{Im}^{\infty}(\widetilde{T})=$ $\operatorname{Im}^{\infty}(T)$.

It clearly suffices to consider only the case when $\operatorname{dim} \operatorname{Im}(F)=1$. As in the proof of $[6$, Theorem, page 194], it is possible to show that $\operatorname{ker}(\widetilde{T}) \stackrel{e}{\subset} \operatorname{Im}^{\infty}(T+F)$. We know that if $\mathrm{M} \stackrel{e}{\subset} \mathrm{N}$ and $\mathrm{M} \stackrel{e}{\subset} \mathrm{L}$, then $\mathrm{M} \stackrel{e}{\subset} \mathrm{N} \cap \mathrm{L}$. Since by Lemma 5.1 , we have

$$
\operatorname{ker}(T+F) \cap \operatorname{Im}\left[(T+F)^{d}\right] \subseteq \operatorname{ker}(T+F) \stackrel{e}{\subset} \operatorname{ker}(T)
$$

and

$$
\operatorname{ker}(T+F) \cap \operatorname{Im}\left[(T+F)^{d}\right] \subseteq \operatorname{Im}\left[(T+F)^{d}\right] \stackrel{e}{\subset} \operatorname{Im}\left(T^{d}\right),
$$

then we can deduce that

$$
\operatorname{ker}(T+F) \cap \operatorname{Im}\left[(T+F)^{d}\right] \stackrel{e}{\subset} \operatorname{ker}(T) \cap \operatorname{Im}\left(T^{d}\right) .
$$

Hence,

$$
\operatorname{ker}(T+F) \cap \operatorname{Im}\left[(T+F)^{d}\right] \stackrel{e}{\complement} \operatorname{ker}(T) \cap \operatorname{Im}\left(T^{d}\right)=\operatorname{ker}(\widetilde{T}) \stackrel{e}{\subset} \operatorname{Im}^{\infty}(T+F)
$$

and since $\operatorname{ker}(T+F) \cap \operatorname{Im}\left[(T+F)^{d}\right] \subseteq \operatorname{ker}(T+F)$, so

$$
\operatorname{ker}(T+F) \cap \operatorname{Im}\left[(T+F)^{d}\right] \stackrel{e}{\complement} \operatorname{ker}(T+F) \cap \operatorname{Im}^{\infty}(T+F) .
$$

This implies that

$$
\alpha=\operatorname{dim}\left(\operatorname{ker}(T+F) \cap \operatorname{Im}\left[(T+F)^{d}\right]\right) /\left(\operatorname{ker}(T+F) \cap \operatorname{Im}^{\infty}(T+F)\right)<+\infty .
$$

Let $n \geq d$ and $\alpha_{n}=\operatorname{dim}\left(\operatorname{ker}(T+F) \cap \operatorname{Im}\left[(T+F)^{d}\right]\right) /\left(\operatorname{ker}(T+F) \cap \operatorname{Im}\left[(T+F)^{n}\right]\right)$. It is clear that the sequence $\left(\alpha_{n}\right)_{n \geq d}$ is increasing and $\alpha_{n} \leq \alpha$, for all $n \geq d$. Then there exist $n_{0} \geq d$ and $\beta \leq \alpha$ such that $\alpha_{n}=\beta$, for all $n \geq n_{0}$. Let $n \geq n_{0}$, since

$\operatorname{ker}(T+F) \cap \operatorname{Im}\left[(T+F)^{n+1}\right] \subseteq \operatorname{ker}(T+F) \cap \operatorname{Im}\left[(T+F)^{n}\right] \subseteq \operatorname{ker}(T+F) \cap \operatorname{Im}\left[(T+F)^{d}\right]$,

we deduce that

$$
\alpha_{n+1}=\alpha_{n}+\operatorname{dim}\left(\operatorname{ker}(T+F) \cap \operatorname{Im}\left[(T+F)^{n}\right]\right) /\left(\operatorname{ker}(T+F) \cap \operatorname{Im}\left[(T+F)^{n+1}\right]\right) .
$$

Thus, $\operatorname{dim}\left(\operatorname{ker}(T+F) \cap \operatorname{Im}\left[(T+F)^{n}\right]\right) /\left(\operatorname{ker}(T+F) \cap \operatorname{Im}\left[(T+F)^{n+1}\right]\right)=\alpha_{n+1}-\alpha_{n}=0$. It follows from this that

$$
\operatorname{ker}(T+F) \cap \operatorname{Im}\left[(T+F)^{n}\right]=\operatorname{ker}(T+F) \cap \operatorname{Im}\left[(T+F)^{n_{0}}\right], \quad \forall n \geq n_{0} .
$$

This means that $q_{0}(T+F) \leq n_{0}$.

$" \Longleftarrow "$ If $q_{0}(T+F)<+\infty$, from the first sense $q_{0}(T)=q_{0}(T+F-F)<+\infty$.

This finishes the proof of the lemma.

The following corollary is a straightforward consequence of Lemma 2.1 and Lemma 5.2 . 
Corollary 5.3. Let $T \in \varphi(\mathrm{H})$ and $F \in \mathscr{B}(\mathrm{H})$ such that $\operatorname{dim} \operatorname{Im}(F)<+\infty, \operatorname{Im}(F) \subset \mathrm{D}(T)$ and $T F x=F T x$, for all $x \in \mathrm{D}(T)$. Then

$$
q_{k}(T)<+\infty \Longleftrightarrow q_{k}(T+F)<+\infty, \quad \forall k \in \mathbb{N} .
$$

Recall that if $T$ and $F$ are bounded operators such $\operatorname{dim} \operatorname{Im}(F)<+\infty$, then $T$ is quasiFredholm if and only if $T+F$ is quasi-Fredholm (see [6, Theorem]). We generalize this result to the class of $\mathrm{k}$-quasi-Fredholm operators as follows :

Theorem 5.4. Let $T \in \varphi(\mathrm{H})$ such that $\varrho_{e}^{+}(T) \neq \emptyset$. Let $F \in \mathscr{B}(\mathrm{H})$ such that $\operatorname{dim} \operatorname{Im}(F)<$ $+\infty, \operatorname{Im}(F) \subset \mathrm{D}(T)$ and $T F x=F T x$, for all $x \in \mathrm{D}(T)$. Then for all $k \in \mathbb{N}$, we have $\sigma_{q \Phi}^{k}(T+F)=\sigma_{q \Phi}^{k}(T)$ and $\sigma_{q \Phi}^{\infty}(T+F)=\sigma_{q \Phi}^{\infty}(T)$.

Proof. Let $k \in \mathbb{N}$ and $T \in k-q \Phi(\mathrm{H})$. By Corollary 5.3, we have $d=\max \left\{q_{k}(T), q_{k}(T+\right.$ $F)\}<+\infty$. It follows from Proposition 4.3 that $\operatorname{Im}\left(T^{d}\right)+\operatorname{ker}\left(T^{k}\right)$ and $\operatorname{Im}(T)+\operatorname{ker}\left(T^{d+k}\right)$ are closed subspaces. From Lemma 5.1, we deduce that $\operatorname{Im}\left[(T+F)^{d}\right]+\operatorname{ker}\left[(T+F)^{k}\right]$ and $\operatorname{Im}(T+F)+\operatorname{ker}\left[(T+F)^{d+k}\right]$ are closed subspaces. Since $d_{1}=q_{k}(T+F) \leq d$, then $\operatorname{Im}(T+F)+\operatorname{ker}\left[(T+F)^{d_{1}+k}\right]$ and $\left(\operatorname{Im}\left[(T+F)^{d_{1}}\right]+\operatorname{ker}\left[(T+F)^{k}\right]\right) \cap \operatorname{ker}\left[(T+F)^{k+1}\right]$ are closed and hence $T+F \in k-q \Phi(\mathrm{H})$. Consequently, $\sigma_{q \Phi}^{k}(T+F)=\sigma_{q \Phi}^{k}(T)$ and

$$
\sigma_{q \Phi}^{\infty}(T+F)=\bigcap_{k \geq 0} \sigma_{q \Phi}^{k}(T+F)=\bigcap_{k \geq 0} \sigma_{q \Phi}^{k}(T)=\sigma_{q \Phi}^{\infty}(T) .
$$

This completes the proof.

As consequence of Proposition 2.7 and Theorem 5.4 we derive the following corollary :

Corollary 5.5. Let $T, F \in \mathscr{B}(\mathrm{H})$ such that $T F=F T$ and $\operatorname{dim} \operatorname{Im}(F)<+\infty$. Then $T$ has topological uniform descent if and only if the same holds for $T+F$.

\section{Remark 5.6.}

(i) Let $k \in \mathbb{N}$. It is clear that if $T=0$, then $T \in k-q \Phi(\mathrm{H})$ and if $K$ is a one-to-one compact operator (so $\operatorname{Im}\left(K^{n}\right)$ is not closed for all $n \in \mathbb{N} \backslash\{0\}$ ), then $K \notin p q \Phi(\mathrm{H})$. Therefore if $T \in p q \Phi(\mathrm{H})$ and $K$ is a compact operator such that $T K=K T$, then it is not necessary that $T+K \in p q \Phi(\mathrm{H})$.

(ii) Let $\mathrm{H}$ be the Hilbert space with an orthonormal basis $\left\{e_{n}: n \in \mathbb{N}\right\}$. Let $T=0$ and $S \in \mathscr{B}(\mathrm{H})$ be defined by

$$
S\left(e_{n}\right)=2^{-n} e_{n+1}, \quad \forall n \in \mathbb{N} .
$$

It is clear that $S$ is quasi-nilpotent and $T S=S T$. Since $\operatorname{Im}(S)$ is not closed and $\operatorname{ker}(S)=\{0\}$, it follows that $T+S$ is not pseudo-quasi-Fredholm. Therefore if $T \in p q \Phi(\mathrm{H})$ and $S$ is a quasi-nilpotent operator such that $T S=S T$, then it is not necessary that $T+S \in p q \Phi(\mathrm{H})$.

Several questions still remain unanswered. Some of these are :

Question 2. Let $T \in \varphi(\mathrm{H})$ and $F \in \mathscr{B}(\mathrm{H})$ such that $\operatorname{Im}(F) \subset \mathrm{D}(T)$ and $T F x=F T x$, for all $x \in \mathrm{D}(T)$.

(i) If $\operatorname{dim} \operatorname{Im}\left(F^{n}\right)<+\infty$, for some $n \in \mathbb{N}$, can we prove that $\sigma_{q \Phi}^{\infty}(T+F)=\sigma_{q \Phi}^{\infty}(T)$ ?

(ii) Suppose that $F$ is a nilpotent operator. We know from [3, Theorem 4.3] that

$$
\sigma_{q \Phi}^{0}(T)=\sigma_{q \Phi}^{0}(T+F) .
$$

Can we prove that $\sigma_{q \Phi}^{k}(T)=\sigma_{q \Phi}^{k}(T+F)$, for all $k \geq 1$ or $\sigma_{q \Phi}^{\infty}(T)=\sigma_{q \Phi}^{\infty}(T+F)$ ?

(iii) If $F$ is s-regular, can we prove that $\sigma_{q \Phi}^{\infty}(T+F)=\sigma_{q \Phi}^{\infty}(T)$ ? 
Remark 5.7. Let $k \in \mathbb{N}$. The set of all $k$-quasi-Fredholm (resp. pseudo-quasi-Fredholm) operators is not open. Indeed, consider the Hilbert space $\mathrm{H}$ with an orthonormal basis $\left\{e_{i, j}, i, j\right.$ integers, $\left.i \geq 1\right\}$. Let $T \in \mathscr{B}(\mathrm{H})$ be defined by

$$
T\left(e_{i, j}\right)= \begin{cases}e_{i, j+1} & \text { if } j \neq 0, \\ 0 & \text { if } j=0 .\end{cases}
$$

Clearly $\operatorname{ker}(T)$ is the subspace of $\mathrm{H}$ spanned by $\left\{e_{i, 0}: i \geq 1\right\}, \operatorname{ker}(T) \subseteq \bigcap_{n \geq 0} \operatorname{Im}\left(T^{n}\right)$ and $\operatorname{Im}(T)$ is closed, so that $T$ is $k$-quasi-Fredholm, for all $k \geq 0$.

Let $\varepsilon>0$. Define $S_{\varepsilon} \in \mathscr{B}(\mathrm{H})$ by

$$
S_{\varepsilon}\left(e_{i, j}\right)= \begin{cases}\frac{\varepsilon}{i+1} e_{i, 1} & \text { if } j=0, \\ 0 & \text { if } j \neq 0 .\end{cases}
$$

Clearly $\left\|S_{\varepsilon}\right\|=\varepsilon$ and $S_{\varepsilon}$ is an infinite dimensional compact operator so that $\operatorname{Im}\left(S_{\varepsilon}\right)$ is not closed. Let $\mathrm{M}$ denote the closed subspace of $\mathrm{H}$ spanned by $\left\{e_{i, 1}, i \geq 1\right\}$. We have $\operatorname{Im}(T) \perp \mathrm{M}$ and $\operatorname{Im}\left(S_{\varepsilon}\right) \subseteq \mathrm{M}$, so that $\left(T+S_{\varepsilon}\right) x \in \mathrm{M}$ implies $x \in \operatorname{ker}(T)$ and $\left(T+S_{\varepsilon}\right) x=S_{\varepsilon} x$. Thus $\operatorname{Im}\left(T+S_{\varepsilon}\right) \cap \mathrm{M}=S_{\varepsilon}(\operatorname{ker}(T))=\operatorname{Im}\left(S_{\varepsilon}\right)$, so that $\operatorname{Im}\left(T+S_{\varepsilon}\right)$ is not closed. Therefore $T+S_{\varepsilon}$ is not pseudo-quasi-Fredholm because $\operatorname{ker}\left(T+S_{\varepsilon}\right)=\{0\}$.

\section{6. $p q$-INDEX OF PSEUDO-QUASI-FREDHOLM}

In this section, we will associate to each pseudo-quasi-Fredholm operator an index " $p q$-index" which coincide with the usual index in the case of a semi-Fredholm operator.

For $T \in \varphi(\mathrm{H})$ and $n, k \in \mathbb{N}$, we denote by

$$
\begin{aligned}
& \alpha_{n}^{k}(T)=\operatorname{dim} \operatorname{ker}\left(T^{k}\right) \cap \operatorname{Im}\left(T^{n}\right), \\
& \beta_{n}^{k}(T)=\operatorname{dim} \operatorname{Im}\left(T^{n}\right) / \operatorname{Im}\left(T^{n+k}\right) .
\end{aligned}
$$

The essential ascent and the essential descent of $T \in \varphi(\mathrm{H})$ are defined by

$$
\begin{aligned}
& \boldsymbol{d}_{\boldsymbol{e}}(T)=\inf \left\{n \in \mathbb{N}: \beta_{n}^{1}(T)<+\infty\right\}, \\
& \boldsymbol{a}_{\boldsymbol{e}}(T)=\inf \left\{n \in \mathbb{N}: \alpha_{n}^{1}(T)<+\infty\right\},
\end{aligned}
$$

respectively, whenever these minima exist. If no such numbers exist the essential ascent and the essential descent of $T$ are defined to be $+\infty$.

Define

$$
\mathscr{A}(\mathrm{H})=\left\{T \in \varphi(\mathrm{H}): \mathrm{D}\left(T^{i}\right)+\operatorname{Im}\left(T^{j}\right)=\mathrm{H}, \quad \forall i, j \in \mathbb{N}\right\} .
$$

Clearly, $\mathscr{A}(\mathrm{H}) \neq \emptyset$, because $T \in \mathscr{A}(\mathrm{H})$, when $T$ is a closed surjective operator.

For $T \in \mathscr{A}(\mathrm{H})$, we can see the following

$$
\begin{aligned}
\beta_{n}^{k}(T) & =\operatorname{dim} \operatorname{Im}\left(T^{n}\right) / \operatorname{Im}\left(T^{n+k}\right), \\
& =\operatorname{dim} \mathrm{D}\left(T^{n}\right) /\left[\operatorname{lm}\left(T^{k}\right)+\operatorname{ker}\left(T^{n}\right)\right] \cap \mathrm{D}\left(T^{n}\right), \\
& =\operatorname{dim}\left[\mathrm{D}\left(T^{n}\right)+\operatorname{Im}\left(T^{k}\right)\right] /\left[\operatorname{Im}\left(T^{k}\right)+\operatorname{ker}\left(T^{n}\right)\right], \\
& =\operatorname{dim} \mathrm{H} /\left[\operatorname{Im}\left(T^{k}\right)+\operatorname{ker}\left(T^{n}\right)\right] .
\end{aligned}
$$

We note from [4, Lemma 2.2] that if $\boldsymbol{a}_{\boldsymbol{e}}(T)<+\infty$, then

$$
q_{0}(T)=\inf \left\{n \in \mathbb{N}: \alpha_{n}^{1}(T)=\alpha_{n+1}^{1}(T)\right\}<+\infty,
$$

and we also note from [4, Lemma 2.5] that if $T \in \mathscr{A}(\mathrm{H})$ such that $\boldsymbol{d}_{\boldsymbol{e}}(T)<+\infty$, then

$$
q_{0}(T)=\inf \left\{n \in \mathbb{N}: \beta_{n}^{1}(T)=\beta_{n+1}^{1}(T)\right\}<+\infty .
$$

We start our study with the following lemma. 
Lemma 6.1. Let $T \in \mathscr{A}(\mathrm{H})$ such that $\operatorname{ker}\left(T^{n}\right) \subseteq \operatorname{Im}(T)$, for all $n \in \mathbb{N}$. Then

$$
\alpha\left(T^{n}\right)=n \alpha(T), \quad \beta\left(T^{n}\right)=n \beta(T), \quad \forall n \in \mathbb{N} \backslash\{0\} .
$$

Proof. Let $n \in \mathbb{N} \backslash\{0\}$, and we consider the following map :

$$
\begin{aligned}
\theta: \operatorname{ker}\left(T^{n}\right) & \longrightarrow \operatorname{ker}\left(T^{n-1}\right) \\
x & \longmapsto T x .
\end{aligned}
$$

Clearly $\theta$ is a surjective linear operator and hence $\alpha\left(T^{n}\right)=\alpha(T)+\alpha\left(T^{n-1}\right)=n \alpha(T)$. Now, we define the following linear operator :

$$
\begin{aligned}
S: \mathrm{D}\left(T^{n-1}\right) & \longrightarrow \mathrm{H} / \operatorname{Im}\left(T^{n}\right) \\
x & \longmapsto \frac{T^{n-1} x}{}
\end{aligned}
$$

Since $\operatorname{ker}(S)=\left[\operatorname{Im}(T)+\operatorname{ker}\left(T^{n-1}\right)\right] \cap \mathrm{D}\left(T^{n-1}\right)=\operatorname{Im}(T) \cap \mathrm{D}\left(T^{n-1}\right)$, we deduce that

$$
\begin{aligned}
\operatorname{Im}\left(T^{n-1}\right) / \operatorname{Im}\left(T^{n}\right) & \approx \mathrm{D}\left(T^{n-1}\right) /\left[\operatorname{Im}(T) \cap \mathrm{D}\left(T^{n-1}\right)\right] \\
& \approx\left[\mathrm{D}\left(T^{n-1}\right)+\operatorname{Im}(T)\right] / \operatorname{Im}(T) \\
& \approx \mathrm{H} / \operatorname{Im}(T) .
\end{aligned}
$$

But, $\operatorname{Im}\left(T^{n}\right) \subseteq \operatorname{Im}\left(T^{n-1}\right) \subseteq \mathrm{H}$, so

$$
\operatorname{dim} \mathrm{H} / \operatorname{Im}\left(T^{n}\right)=\operatorname{dim} \mathrm{H} / \operatorname{Im}\left(T^{n-1}\right)+\operatorname{dim} \operatorname{Im}\left(T^{n-1}\right) / \operatorname{Im}\left(T^{n}\right) .
$$

Therefore

$$
\beta\left(T^{n}\right)=\beta\left(T^{n-1}\right)+\beta(T)=n \beta(T) .
$$

This completes the proof.

Lemma 6.2. Let $T \in \mathscr{A}(\mathbf{H})$ such that $\min \left\{\boldsymbol{d}_{\boldsymbol{e}}(T), \boldsymbol{a}_{\boldsymbol{e}}(T)\right\}<+\infty$ and let $p=q_{0}(T)<$ $+\infty$. Then for all $n \geq p$, we have

$$
\alpha_{n}^{k}(T)=k \alpha_{p}^{1}(T), \quad \beta_{n}^{k}(T)=k \beta_{p}^{1}(T), \quad \forall k \in \mathbb{N} \backslash\{0\} .
$$

Proof. Let $m \geq p$ and let $\widetilde{T_{m}}$ be the operator induced by $T$ on $\mathrm{H} / \operatorname{ker}\left(T^{m}\right)$. Since $\operatorname{ker}\left[\left(\widetilde{T_{m}}\right)^{n}\right] \subseteq \operatorname{Im}\left(\widetilde{T_{m}}\right)$, for every $n \in \mathbb{N}$, by Lemma 6.1 , we get

$$
\beta_{m}^{k}(T)=\beta\left(\widetilde{T_{m}}{ }^{k}\right)=k \beta\left(\widetilde{T_{m}}\right)=k \beta_{m}^{1}(T)=k \beta_{p}^{1}(T), \quad \forall k \geq 1
$$

and

$$
\alpha_{m}^{k}(T)=\alpha\left(\widetilde{T_{m}}{ }^{k}\right)=k \alpha\left(\widetilde{T_{m}}\right)=k \alpha_{m}^{1}(T)=k \alpha_{p}^{1}(T), \quad \forall k \geq 1 .
$$

This completes the proof.

Remark 6.3. Let $k, d \in \mathbb{N}$ and $T \in k-q \Phi(d)(\mathrm{H})$ such that $\boldsymbol{a}_{\boldsymbol{e}}(T)<+\infty$ or $\boldsymbol{d}_{\boldsymbol{e}}(T)<+\infty$. Let $m=\min \left\{\boldsymbol{a}_{\boldsymbol{e}}(T), \boldsymbol{d}_{\boldsymbol{e}}(T)\right\}$, we denote by

$$
\delta_{m}^{k}(T)=\alpha_{m}^{k}(T)-\beta_{m}^{k}(T) \in \mathbb{Z} \cup\{-\infty,+\infty\} .
$$

If $T \in \mathscr{A}(\mathrm{H})$ from [4, Lemma 2.2, Lemma 2.5], we deduce that $\delta_{m}^{k}(T)=\delta_{n}^{k}(T)$, for all $n \geq m$. Therefore for $k \in \mathbb{N} \backslash\{0\}$, by Lemma 6.2 , we obtain

$$
\begin{aligned}
\delta_{m}^{k}(T)=\delta_{q_{0}(T)}^{k}(T) & =\alpha_{q_{0}(T)}^{k}(T)-\beta_{q_{0}(T)}^{k}(T) \\
& =k \alpha_{q_{0}(T)}^{1}(T)-k \beta_{q_{0}(T)}^{1}(T) \\
& =k \delta_{q_{0}(T)}^{1}(T) \\
& =k \delta_{m}^{1}(T) .
\end{aligned}
$$

Remark 6.3 enables us to define the $p q$-index of pseudo-quasi-Fredholm operator.

Definition 6.4. We say that an operator $T \in p q \Phi(\mathrm{H})$ possesses $p q$-index if $\ell=\min \left\{\boldsymbol{a}_{\boldsymbol{e}}(T)\right.$, $\left.\boldsymbol{d}_{\boldsymbol{e}}(T)\right\}<+\infty$, in this case the $p q$-index of $T$ is defined by

$$
\operatorname{ind}_{p q}(T)=\alpha_{\ell}^{1}(T)-\beta_{\ell}^{1}(T) \in \mathbb{Z} \cup\{-\infty,+\infty\} .
$$




\section{Example 6.5.}

(i) Let $T$ be a pseudo-quasi-Fredholm operator such that $\boldsymbol{a}(T)<+\infty$ (resp. $\boldsymbol{d}(T)<$ $+\infty, \max \{\boldsymbol{a}(T), \boldsymbol{d}(T)\}<+\infty)$, then $T$ possesses a $p q$-index and $\operatorname{ind}_{p q}(T) \leq 0$ $\left(\operatorname{resp} \operatorname{ind}_{p q}(T) \geq 0, \operatorname{ind}_{p q}(T)=0\right)$.

(ii) Let $\mathrm{H}$ be the Hilbert space with an orthonormal basis $\left\{e_{i, j}: i, j \in \mathbb{N} \backslash\{0\}\right\}$. Let $T \in \mathscr{B}(\mathrm{H})$ be defined by

$$
T\left(e_{i, j}\right)= \begin{cases}0 & \text { if } i=1 \\ e_{i, j+1} & \text { if } i \geq 2 .\end{cases}
$$

Clearly $\operatorname{ker}\left(T^{k}\right)\left(\right.$ resp. $\left.\operatorname{Im}\left(T^{k}\right)\right)$ is the subspace of $\mathbf{H}$ spanned by $\left\{e_{1, j}: j \geq 1\right\}$ (resp. $\left\{e_{i, j}: i \geq 2, j \geq k+1\right\}$ ), for all $k \geq 1$, so that $q_{0}(T)=\boldsymbol{a}(T)=\boldsymbol{a}_{\boldsymbol{e}}(T)=1$ and $\boldsymbol{d}_{\boldsymbol{e}}(T)=+\infty$. Since $\operatorname{Im}(T)$ is closed and $\operatorname{Im}(T) \perp \operatorname{ker}(T)$, then $\operatorname{Im}(T)+\operatorname{ker}(T)$ is closed, this implies that $T$ is $k$-quasi-Fredholm of degree $q_{k}(T)=\max \{1-k, 0\}$, for every $k \in \mathbb{N}$ and the $p q$-index of $T$ is equal to

$$
\operatorname{ind}_{p q}(T)=\alpha_{1}^{1}(T)-\beta_{1}^{1}(T)=-\infty .
$$

Moreover, $T \notin \Phi_{ \pm}(\mathrm{H})$, but there exists $\varepsilon>0$ such that $\lambda I-T \in \Phi_{+}(\mathrm{H})$ and $\alpha(\lambda I-T)=0$, for all $\lambda \in \mathbb{C}$ and $0<|\lambda|<\varepsilon$ according to Lemma 3.1.

Remark 6.6. Let $k \in \mathbb{N}$ and $T \in \varphi(\mathrm{H})$ such that $\varrho(T) \neq \emptyset$ (in particular $T \in \mathscr{A}(\mathrm{H})$ ). If $T \in k-q \Phi(\mathrm{H})$ possesses $p q$-index, then $T^{n} \in k-q \Phi(\mathrm{H})$ and $\operatorname{ind}_{p q}\left(T^{n}\right)=n \operatorname{ind}_{p q}(T)$, for all $n \in \mathbb{N} \backslash\{0\}$. Indeed, by Lemma 4.5 and Remark 4.18, it follows that $T^{n} \in k-q \Phi(\mathrm{H})$ and by [4, Lemma 2.1], we infer that $T^{n}$ possesses $p q$-index. Let $d=q_{0}\left(T^{n}\right)$, since

$$
\operatorname{ker}\left(T^{j}\right) \subseteq \operatorname{ker}\left[\left(T^{n}\right)^{j}\right] \subseteq \operatorname{Im}\left(T^{n}\right)+\operatorname{ker}\left[\left(T^{n}\right)^{d}\right] \subseteq \operatorname{Im}(T)+\operatorname{ker}\left(T^{d n}\right), \quad \forall j \in \mathbb{N},
$$

then $l=q_{0}(T) \leq n d$. From Remark 6.3, we obtain

$$
\begin{aligned}
\operatorname{ind}_{p q}\left(T^{n}\right) & =\alpha_{d}^{1}\left(T^{n}\right)-\beta_{d}^{1}\left(T^{n}\right) \\
& =\alpha_{n d}^{n}(T)-\beta_{n d}^{n}(T) \\
& =\delta_{n d}^{n}(T)=\delta_{l}^{n}(T)=n \delta_{l}^{1}(T)=n \operatorname{ind}_{p q}(T) .
\end{aligned}
$$

Proposition 6.7. Let $T \in \varphi(\mathrm{H})$ such that $\varrho_{e}^{+}(T) \neq \emptyset$ and $k \in \mathbb{N}$. If $\boldsymbol{a}_{e}(T)<+\infty$, then

$$
T \in k-q \Phi(\mathrm{H}) \Longleftrightarrow \operatorname{Im}(T)+\operatorname{ker}\left(T^{a_{e}(T)}\right) \quad \text { is closed. }
$$

Proof. " $\Longrightarrow$ " Let $d=q_{k}(T)$, by Lemma 2.1, we have $d+k \geq q_{0}(T) \geq \boldsymbol{a}_{\boldsymbol{e}}(T)$ and as $\operatorname{Im}(T)+\operatorname{ker}\left(T^{d+k}\right)$ is closed, then from [4, Lemma 3.3], we get $\operatorname{Im}(T)+\operatorname{ker}\left(T^{a_{e}(T)}\right)$ is closed.

$" \Longleftarrow "$ Since $\boldsymbol{a}_{\boldsymbol{e}}(T)$ is finite, then $q_{0}(T)$ is also finite and hence $d=q_{k}(T)=\max \left\{q_{0}(T)-\right.$ $k, 0\}<+\infty$ according to Lemma 2.1. As $d+k \geq q_{0}(T) \geq \boldsymbol{a}_{\boldsymbol{e}}(T)$, then we can deduce from [4, Lemma 3.3], that $\operatorname{Im}(T)+\operatorname{ker}\left(T^{d+k}\right)$ is closed. Let $m=\max \left\{d, \boldsymbol{a}_{\boldsymbol{e}}(T)\right\}$, we have $\operatorname{dim} \operatorname{lm}\left(T^{m}\right) \cap \operatorname{ker}\left(T^{k+1}\right)<+\infty$, this gives that

$$
\operatorname{Im}\left(T^{d}\right) \cap \operatorname{ker}\left(T^{k+1}\right)+\operatorname{ker}\left(T^{k}\right)=\operatorname{Im}\left(T^{m}\right) \cap \operatorname{ker}\left(T^{k+1}\right)+\operatorname{ker}\left(T^{k}\right) \quad \text { is closed. }
$$

Hence, $T \in k-q \Phi(\mathrm{H})$ and the proof of the lemma is complete.

Proposition 6.8. Let $T \in \mathscr{A}(\mathrm{H})$ such that $\varrho_{e}^{+}(T) \neq \emptyset$ and $\boldsymbol{d}_{\boldsymbol{e}}(T)<+\infty$. Then

$$
T \in k-q \Phi(\mathrm{H}), \quad \forall k \geq \boldsymbol{d}_{\boldsymbol{e}}(T) .
$$

Proof. For $n \in \mathbb{N}$ and $i \in \mathbb{N} \backslash\{0\}$, we have

$$
\beta_{n}^{1}(T) \leq \beta_{n}^{i}(T)=\beta\left({\widetilde{T_{n}}}^{i}\right) \leq i \beta\left(\widetilde{T_{n}}\right)=i \beta_{n}^{1}(T),
$$

where $\widetilde{T_{n}}$ is the operator induced by $T$ on $\mathrm{H} / \operatorname{ker}\left(T^{n}\right)$. This implies that

$$
\beta_{n}^{1}(T)<+\infty \Longleftrightarrow \beta_{n}^{i}(T)<+\infty \text {. }
$$


Let $k \geq \boldsymbol{d}_{\boldsymbol{e}}(T)$ and $d=q_{k}(T)=\max \left\{q_{0}(T)-k, 0\right\}<+\infty$. Since

$$
\operatorname{dim} \mathrm{H} /\left[\operatorname{Im}(T)+\operatorname{ker}\left(T^{d+k}\right)\right]=\beta_{d+k}^{1}(T)<+\infty
$$

and

$$
\operatorname{dim} \mathrm{H} /\left[\operatorname{lm}\left(T^{d}\right)+\operatorname{ker}\left(T^{k}\right)\right]=\beta_{k}^{d}(T)<+\infty,
$$

then $\operatorname{Im}(T)+\operatorname{ker}\left(T^{d+k}\right)$ and $\left[\operatorname{Im}\left(T^{d}\right)+\operatorname{ker}\left(T^{k}\right)\right] \cap \operatorname{ker}\left(T^{k+1}\right)$ are closed (see Lemma 2.9 and [7, Proposition 2.1.1]). This completes the proof.

Remark 6.9. By Propositions 6.7 and 6.8 , we remark that, we can replace the hypothesis of Definition 6.4 by : let $T \in \mathscr{A}(\mathrm{H})$ such that $\varrho_{e}^{+}(T) \neq \emptyset$ and $\boldsymbol{d}_{\boldsymbol{e}}(T)<+\infty$ or $\boldsymbol{a}_{\boldsymbol{e}}(T)<$ $+\infty$ and $\operatorname{Im}(T)+\operatorname{ker}\left(T^{a_{e}(T)}\right)$ is closed. If additionally $T \in \mathscr{B}(\mathrm{H})$, then $T$ is semi-BFredholm and the $p q$-index coincide with the index of a semi-B-Fredholm operator [1].

Theorem 6.10. Let $k \in \mathbb{N}$ and $T \in k-q \Phi(\mathrm{H})$ such that $\varrho(T) \neq \emptyset$. Let $F \in \mathscr{B}(\mathrm{H})$ such that $\operatorname{dim} \operatorname{Im}(F)<+\infty, \operatorname{Im}(F) \subset \mathrm{D}(T)$ and $T F x=F T x$, for all $x \in \mathrm{D}(T)$. If $T$ possesses pq-index, then $T+F \in k-q \Phi(\mathrm{H}), T+F$ possesses pq-index and $\operatorname{ind}_{p q}(T+F)=\operatorname{ind}_{p q}(T)$.

Proof. From Theorem 5.4, we have $T+F \in k-q \Phi(\mathrm{H})$. According to Lemma 2.1 and Corollary 5.3, $d=\max \left\{q_{k}(T), q_{k}(T+F)\right\}$ and $p=\max \left\{q_{0}(T), q_{0}(T+F)\right\}$ are finite. By Lemma 3.1, we know that there exists $\lambda \in \mathbb{C} \backslash\{0\}$ such that

$$
\begin{gathered}
\alpha\left(T_{\lambda}\right)=\alpha_{d+k}^{1}(T)=\alpha_{p}^{1}(T), \beta\left(T_{\lambda}\right)=\beta_{d+k}^{1}(T)=\beta_{p}^{1}(T), \\
\alpha(\lambda I-T-F)=\alpha_{d+k}^{1}(T+F)=\alpha_{p}^{1}(T+F), \\
\beta(\lambda I-T-F)=\beta_{d+k}^{1}(T+F)=\beta_{p}^{1}(T+F) .
\end{gathered}
$$

So, $T_{\lambda} \in \Phi_{ \pm}(\mathrm{H})$, consequently $(T+F)_{\lambda} \in \Phi_{ \pm}(\mathrm{H})$ and

$$
l=\min \left\{\boldsymbol{a}_{\boldsymbol{e}}(T+F), \boldsymbol{d}_{\boldsymbol{e}}(T+F)\right\} \leq p .
$$

Now since $j=\min \left\{\boldsymbol{a}_{\boldsymbol{e}}(T), \boldsymbol{d}_{\boldsymbol{e}}(T)\right\} \leq p$, then

$$
\begin{aligned}
\operatorname{ind}_{p q}(T) & =\alpha_{j}^{1}(T)-\beta_{j}^{1}(T)=\alpha_{p}^{1}(T)-\beta_{p}^{1}(T)=\operatorname{ind}\left(T_{\lambda}\right) \\
& =\operatorname{ind}\left[(T+F)_{\lambda}\right]=\alpha_{p}^{1}(T+F)-\beta_{p}^{1}(T+F) \\
& =\alpha_{l}^{1}(T+F)-\beta_{l}^{1}(T+F)=\operatorname{ind}_{p q}(T+F) .
\end{aligned}
$$

This completes the proof.

Remark 6.11. Let $k \in \mathbb{N}$ and $T \in k-q \Phi(\mathrm{H})$ such that $\varrho(T) \neq \emptyset$. From the proof of Theorem 6.10 , we see that if $T$ possesses $p q$-index, then there exists $\varepsilon>0$ such that $T_{\lambda} \in \Phi_{ \pm}(\mathrm{H})$ and $\operatorname{ind}\left(T_{\lambda}\right)=\operatorname{ind}_{p q}(T)$, for every $0<|\lambda|<\varepsilon$.

Theorem 6.12. Let $d, k \in \mathbb{N}, T \in k-q \Phi(d)(\mathrm{H})$ and $V \in \mathscr{B}(\mathrm{H})$. Suppose that $T$ is a bounded operator that commutes with $V$ and $V-T$ is sufficiently small and invertible, then :

(i) $V$ is a s-regular operator,

(ii) $\alpha_{n}^{1}(V)=\alpha_{d+k}^{1}(T)$, for all $n \geq 0$,

(iii) $\beta_{n}^{1}(V)=\beta_{d+k}^{1}(T)$, for all $n \geq 0$.

Proof. It follows from Lemma 2.1 and Proposition 2.7 that $T$ has topological uniform descent for $n \geq d+k$. The result now follows from [5, Theorem 4.7].

Corollary 6.13. Let $T, V \in \mathscr{B}(\mathrm{H})$ such that $T V=V T$ and $V$ is sufficiently small and invertible. If $T \in p q \Phi(\mathrm{H})$, then $T+V \in p q \Phi(\mathrm{H})$.

Corollary 6.14. Let $d, k \in \mathbb{N}, T \in k-q \Phi(d)(\mathrm{H})$ and $V \in \mathscr{B}(\mathrm{H})$. Suppose that $T$ is a bounded operator that commutes with $V$ and $V-T$ is sufficiently small and invertible, then:

(i) $V$ has infinite ascent or descent if and only if $T$ does. 
(ii) $V$ is onto if and only if $T$ has finite descent.

(iii) $V$ is one-to-one (or bounded below) if and only if $T$ has finite ascent.

(iv) $V$ is invertible if and only if $0 \in \mathrm{E}(T)$.

$(v) V$ is semi-Fredholm if and only if $T$ possesses pq-index. If $V \in \Phi_{ \pm}(\mathrm{H})$, then

$$
\operatorname{ind}_{p q}(T)=\operatorname{ind}(V)=\alpha_{n}^{1}(V)-\beta_{n}^{1}(V), \quad \forall n \geq 0 .
$$

Theorem 6.15. Let $V, T \in p q \Phi(\mathrm{H})$. Suppose that $V, T \in \mathscr{B}(\mathrm{H})$ such that $T V=V T$ and $V-T$ is sufficiently small, then $T$ possesses pq-index if and only if $V$ possesses pq-index. If $T$ or $V$ possesses pq-index, then

$$
\operatorname{ind}_{p q}(T)=\operatorname{ind}_{p q}(V) .
$$

Proof. Let $k_{1}, k_{2}, d_{1}, d_{2} \in \mathbb{N}$ such that $T \in k_{1}-q \Phi\left(d_{1}\right)(\mathrm{H})$ and $V \in k_{2}-q \Phi\left(d_{2}\right)(\mathrm{H})$, then $T$ and $V$ having topological uniform descent for $n \geq \max \left\{d_{1}+k_{1}, d_{2}+k_{2}\right\}$. Now the proof follows from [5, Theorem 4.6].

\section{EXAMPLES}

In this section we present some examples that are applications of the abstract theory of the pseudo-quasi-Fredholm.

Example 7.1. In $\mathrm{H}=L^{2}([0,1])$ define the second-order differential operator $T$ by

$$
\mathrm{D}(T)=\left\{u \in \mathrm{H}^{2}([0,1]): u^{\prime}(0)+u^{\prime}(1)=0, u(0)=0\right\}, \quad T u=-u^{\prime \prime},
$$

where $\mathrm{H}^{2}([0,1])$ denotes the subspace of $\mathrm{H}$ consisting of all functions $u \in \mathrm{C}^{1}([0,1])$ with $u^{\prime}$ absolutely continuous on $[0,1]$ and $u^{\prime \prime} \in \mathrm{H}$. Then $T$ is a discrete operator in H. In [4, Example 3.12], it is proved that $\sigma(T)=\left\{\lambda_{i}\right\}_{i=1}^{\infty}$ where $\lambda_{i}=(2 i-1)^{2} \pi^{2}$, and $\boldsymbol{a}\left(\lambda_{i} I-T\right)=\boldsymbol{d}\left(\lambda_{i} I-T\right)=2$, for $i=1,2, \ldots$. This shows that $q_{0}\left(\lambda_{i} I-T\right)=2$,

$$
\begin{gathered}
\operatorname{Im}\left(\lambda_{i} I-T\right)+\operatorname{ker}\left[\left(\lambda_{i} I-T\right)^{n}\right]=\mathrm{H}, \\
\operatorname{Im}\left[\left(\lambda_{i} I-T\right)^{n}\right] \cap \operatorname{ker}\left[\left(\lambda_{i} I-T\right)^{j+1}\right]+\operatorname{ker}\left[\left(\lambda_{i} I-T\right)^{j}\right]=\operatorname{ker}\left[\left(\lambda_{i} I-T\right)^{j}\right],
\end{gathered}
$$

for all $j \in \mathbb{N}, n \geq 2$ and $i \geq 1$. For $i \geq 1$ and $k \in \mathbb{N}$, by Lemma 2.1, we obtain $\lambda_{i} I-T$ is $k$-quasi-Fredholm of degree $d_{k}=\max \{2-k, 0\}$. Hence $\mathbb{C}=\varrho(T) \cup \sigma(T) \subseteq \varrho_{q \Phi}^{k}(T)$ i.e., $\sigma_{q \Phi}^{k}(T)=\sigma_{q \Phi}^{\infty}(T)=\emptyset$, for all $k \in \mathbb{N}$.

Remark 7.2. If $T \in \mathscr{B}(\mathrm{H})$ by Theorem 3.4, we observe that

$$
\sigma_{q \Phi}^{\infty}(T)=\emptyset \Longrightarrow \sigma(T)=\left\{\lambda_{1}, \lambda_{2}, \ldots, \lambda_{n}\right\}=\mathrm{E}(T),
$$

for some $\lambda_{1}, \lambda_{2}, \ldots, \lambda_{n} \in \mathbb{C}$. From Example 7.1 the conclusion (1) fails when $\mathrm{D}(T) \varsubsetneqq \mathrm{H}$.

Example 7.3. Consider the operator $S$ defined on $\ell^{2}(\mathbb{N})$ by

$$
S\left(x_{1}, x_{2}, x_{3}, \ldots\right)=\left(\frac{x_{2}}{2}, \frac{x_{3}}{3}, \frac{x_{4}}{4}, \ldots\right)
$$

and the operator $T$ defined on $\ell^{2}(\mathbb{N}) \times \ell^{2}(\mathbb{N})$ by

$$
T\left(\left(x_{1}, x_{2}, x_{3}, \ldots\right),\left(y_{1}, y_{2}, y_{3}, \ldots\right)\right)=\left(\left(0, x_{2}, x_{3}, \ldots\right), S\left(y_{1}, y_{2}, y_{3}, \ldots\right)\right) \text {. }
$$

(a) It is clear that $S$ is a quasi-nilpotent operator and $\operatorname{dim} \operatorname{ker}\left(S^{n}\right)=n$, for all $n \in \mathbb{N}$. Thus, $\sigma_{q \Phi}^{\infty}(S) \subseteq \sigma_{q \Phi}^{k}(S) \subseteq \sigma(S)=\{0\}$, for all $k \in \mathbb{N}$. Suppose that $\sigma_{q \Phi}^{\infty}(S)=\emptyset$, then by Theorem 3.4, $T$ is algebraic. This implies that $\mathrm{E}(S)=\{0\}$, which is a contradiction because $\boldsymbol{a}(S)=+\infty$. It follows that $\sigma_{q \Phi}^{\infty}(S)=\{0\}$ and hence $\sigma_{q \Phi}^{k}(S)=\{0\}$, for all $k \in \mathbb{N}$. Let $f$ be an analytic function in a neighborhood of the usual spectrum $\sigma(S)$ and not locally constant in a neighborhood of 0 and $f(0) \neq 0$, then by Corollary 4.17, $f(S)$ is a k-quasi-Fredholm operator, for all $k \in \mathbb{N}$. 
(b) Let $F \in \mathscr{B}\left(\ell^{2}(\mathbb{N}) \times \ell^{2}(\mathbb{N})\right)$ be defined by

$$
F\left(\left(x_{1}, x_{2}, x_{3}, \ldots\right),\left(y_{1}, y_{2}, y_{3}, \ldots\right)\right)=\left(\left(x_{1}, 0,0, \ldots\right),(0,0,0, \ldots)\right) .
$$

Note that $(T+F)(x, y)=(x, S y)$, for all $x, y \in \ell^{2}(\mathbb{N})$, which implies that $\sigma_{p q}^{k}(T+$ $F)=\sigma_{p q}^{k}(I) \cup \sigma_{p q}^{k}(S)=\{0\}$, because $\sigma_{p q}^{k}(I)=\emptyset$, for all $k \in \mathbb{N}$. Furthermore, since $\operatorname{dim} \operatorname{Im}(F)=1$ and $T F=F T=0$, by Theorem 5.4, it follows that

$$
\sigma_{p q}^{k}(T)=\sigma_{p q}^{k}(T+F)=\{0\}, \quad \forall k \in \mathbb{N} .
$$

Example 7.4. For each $n \in \mathbb{N} \backslash\{0\}$, set

$$
\nu(n)=\max \left\{k \in \mathbb{N}: 2^{k} \text { divides } n\right\} .
$$

Let $T \in \mathscr{B}\left(\ell^{2}(\mathbb{N})\right)$ be defined by

$$
T\left(\sum_{n=0}^{+\infty} x_{n} e_{n}\right)=\sum_{n=1}^{+\infty} \frac{1}{2^{\nu(n)}} x_{n} e_{n},
$$

with $\left\{e_{n}: n \in \mathbb{N}\right\}$ is an orthonormal basis of $\ell^{2}(\mathbb{N})$.

(a) We remark that $\operatorname{ker}(T)$ is the subspace of $\ell^{2}(\mathbb{N})$ spanned by $e_{0}$, which gives $\boldsymbol{a}_{\boldsymbol{e}}(T)=0$.

Since $\operatorname{Im}(T)$ is easily seen to be non-closed, it follows from Proposition 6.7 that

$$
T \notin k-q \Phi\left(\ell^{2}(\mathbb{N})\right), \quad \forall k \in \mathbb{N} .
$$

Now Proposition 6.8 gives $\boldsymbol{d}_{\boldsymbol{e}}(T)=+\infty$.

(b) It is not difficult to see that

$$
\sigma(T)=\{0\} \cup\left\{\lambda_{n}=\frac{1}{2^{n}}: n \in \mathbb{N}\right\} .
$$

Besides, for each $n \in \mathbb{N}$, $\operatorname{ker}\left(\lambda_{n} I-T\right)$ is the closed subspace of $\ell^{2}(\mathbb{N})$ spanned by $\left\{e_{2^{n}(2 j+1)}: j \in \mathbb{N}\right\}$, and $\operatorname{Im}\left(\lambda_{n} I-T\right)=\operatorname{ker}\left(\lambda_{n} I-T\right)^{\perp}$. It follows that $\boldsymbol{a}\left(\lambda_{n} I-T\right)=$ $\boldsymbol{d}\left(\lambda_{n} I-T\right)=1$. Since $\operatorname{Im}\left[\left(\lambda_{n} I-T\right)^{i}\right]+\operatorname{ker}\left[\left(\lambda_{n} I-T\right)^{j}\right]=\ell^{2}(\mathbb{N})$ and $\operatorname{Im}\left[\left(\lambda_{n} I-T\right)^{i}\right] \cap$ $\operatorname{ker}\left[\left(\lambda_{n} I-T\right)^{j}\right]=\{0\}$, for all $i, j \geq 1$, it follows that $\lambda_{n} \in \varrho_{q \Phi}^{k}(T)$, for all $n, k \in \mathbb{N}$. This shows that $\mathbb{C} \backslash\{0\} \subseteq \varrho_{q \Phi}^{k}(T)$, and as $0 \in \sigma_{q \Phi}^{k}(T)$, we obtain

$$
\sigma_{q \Phi}^{\infty}(T)=\sigma_{q \Phi}^{k}(T)=\{0\}, \quad \forall k \in \mathbb{N} .
$$

(c) Since for all $\lambda \in \sigma(T) \backslash\{0\}$, we have $\boldsymbol{a}(\lambda I-T)=\boldsymbol{d}(\lambda I-T)=1$, it follows that $\lambda I-T \in p q \Phi\left(\ell^{2}(\mathbb{N})\right)$ possesses $p q$-index, for all $\lambda \in \mathbb{C} \backslash\{0\}$. Furthermore, since $\max \{\boldsymbol{a}(\lambda I-T), \boldsymbol{d}(\lambda I-T)\} \leq 1$, for all $\lambda \in \mathbb{C} \backslash\{0\}$, by Remark 6.3, we deduce that

$$
\operatorname{ind}_{p q}(\lambda I-T)=\alpha_{1}^{1}(\lambda I-T)-\beta_{1}^{1}(\lambda I-T)=0 .
$$

(d) Fix $c \in \mathbb{C}$ and consider the polynomial $P$ defined by $P(Z)=c$. Then $P(T)=c I$. Since $\sigma_{q \Phi}^{\infty}(T)$ is nonempty, it follows that

$$
P\left(\sigma_{q \Phi}^{\infty}(T)\right)=\{c\} .
$$

However, $\varrho_{q \Phi}^{\infty}(P(T))=\mathbb{C}$ : indeed, $\mathbb{C} \backslash\{c\}=\varrho(c I) \subseteq \varrho_{q \Phi}^{\infty}(c I)$, and $c I-c I$ (that is, the zero operator on $\left.\ell^{2}(\mathbb{N})\right)$ is pseudo-quasi-Fredholm. Consequently, $\varrho_{q \Phi}^{\infty}(P(T))=\mathbb{C}$ and

$$
\sigma_{q \Phi}^{\infty}(P(T))=\emptyset \neq P\left(\sigma_{q \Phi}^{\infty}(T)\right) .
$$

Hence the conclusion of Theorem 4.12 fails in the presence of a constant complex polynomial. 
Example 7.5. Consider the infinite-dimensional complex Hilbert space $\mathrm{H}=\mathbb{C}^{3} \times \ell^{2}(\mathbb{N})$ and the operator $T \in \mathscr{B}(\mathrm{H})$ defined by

$$
T\left(\left(z_{1}, z_{2}, z_{3}\right), \sum_{n=0}^{+\infty} x_{n} e_{n}\right)=\left(\left(z_{2}, 0,0\right), z_{3} e_{0}+\sum_{n=0}^{+\infty} x_{n+1} e_{n}\right),
$$

where $\left\{e_{n}: n \in \mathbb{N}\right\}$ is an orthonormal basis of $\ell^{2}(\mathbb{N})$.

(a) We remark that

$$
\operatorname{ker}(T)=\left\{\left(\left(z_{1}, z_{2}, z_{3}\right),\left(x_{n}\right)_{n \in \mathbb{N}}\right) \in \mathrm{H}: z_{2}=0, x_{1}=-z_{3}, x_{n}=0, \forall n \geq 2\right\}
$$

and

$$
\operatorname{Im}(T)=\left\{\left(\left(z_{1}, z_{2}, z_{3}\right),\left(x_{n}\right)_{n \in \mathbb{N}}\right) \in \mathrm{H}: z_{2}=z_{3}=0\right\} .
$$

Hence $\alpha(T)=3$ and $\beta(T)=2$, and consequently

$$
\operatorname{Im}\left(T^{i}\right) \cap \operatorname{ker}\left(T^{j+1}\right)+\operatorname{ker}\left(T^{j}\right) \text { and } \operatorname{Im}(T)+\operatorname{ker}\left(T^{j}\right) \quad \text { are closed, } \quad \forall i, j \in \mathbb{N} .
$$

We observe that, for all $k \geq 2$,

$$
T^{k}\left(\left(z_{1}, z_{2}, z_{3}\right), \sum_{n=0}^{+\infty} x_{n} e_{n}\right)=\left((0,0,0), \sum_{n=0}^{+\infty} x_{n+k} e_{n}\right) .
$$

Hence

$$
\operatorname{Im}\left(T^{k}\right)=\{0\} \times \ell^{2}(\mathbb{N}), \quad \forall k \geq 2
$$

Therefore,

$\operatorname{ker}(T) \cap \operatorname{Im}(T)=\left\{\left(\left(z_{1}, z_{2}, z_{3}\right),\left(x_{n}\right)_{n \in \mathbb{N}}\right) \in \mathbf{H}: z_{2}=z_{3}=0, x_{n}=0, \forall n \geq 1\right\}$,

and, for all $k \geq 2$,

$\operatorname{ker}(T) \cap \operatorname{Im}\left(T^{k}\right)=\left\{\left(\left(z_{1}, z_{2}, z_{3}\right),\left(x_{n}\right)_{n \in \mathbb{N}}\right) \in \mathbf{H}: z_{1}=z_{2}=z_{3}=0, x_{n}=0, \forall n \geq 1\right\}$.

Thus

$$
q_{0}(T)=\inf \left\{k \in \mathbb{N}: \operatorname{ker}(T) \cap \operatorname{Im}\left(T^{k}\right)=\operatorname{ker}(T) \cap \operatorname{Im}\left(T^{m}\right), \quad \forall m \geq k\right\}=2 .
$$

For $k \geq 2$, by using (1) and Lemma 2.1, we obtain that $T$ is a quasi-Fredholm (resp. 1-quasi-Fredholm, $k$-quasi-Fredholm) operator of degree $d=2$ (resp. $d=1, d=0)$.

(b) Recall that the reduced minimum modulus of a non-zero operator $A \in \mathscr{B}(\mathrm{H})$ is defined by

$$
\gamma(A)=\inf \left\{\|A x\|: x \in \operatorname{ker}(A)^{\perp} \text { and }\|x\|=1\right\} .
$$

If $A=0$ then we take $\gamma(A)=+\infty$. Now let $S \in \ell^{2}(\mathbb{N})$ be defined by

$$
S\left(\sum_{n=0}^{+\infty} x_{n} e_{n}\right)=\sum_{n=0}^{+\infty} x_{n+2} e_{n} .
$$

We note from (2) that

$$
\left(\lambda I-T^{2}\right)(z, x)=(\lambda z,(\lambda I-S) x), \quad \forall(z, x) \in \mathbb{C}^{3} \times \ell^{2}(\mathbb{N}), \quad \forall \lambda \in \mathbb{C} .
$$

It is clear that $S$ is Fredholm $(\alpha(S)=2, \beta(S)=0)$ and $\gamma(S)=\|S\|=1$. Therefore, for all $\lambda_{1}, \lambda_{2} \in \mathbb{C}$ such that $\left|\lambda_{1}\right|<1=\gamma(S)$ and $\left|\lambda_{2}\right|>1=\|S\|$, we have $\lambda_{1} I-S$ is Fredholm and $\lambda_{2} I-S$ is invertible. Since $T$ is Fredholm it follows from (3) that $\lambda I-T^{2}$ is Fredholm for all $\lambda \in \mathbb{C}$ such that $|\lambda| \neq 1$. Consequently, $\sigma_{q \Phi}^{\infty}\left(T^{2}\right) \subseteq\{\lambda \in$ $\mathbb{C}:|\lambda|=1\}$ and $\sigma_{q \Phi}^{k}\left(T^{2}\right) \subseteq\{\lambda \in \mathbb{C}:|\lambda|=1\}$, for all $k \in \mathbb{N}$. Now by Theorem 4.12, we see that if $\lambda \in \sigma_{q \Phi}^{\infty}(T)$ then $\left|\lambda^{2}\right|=1$, this implies that $|\lambda|=1$. Hence

$$
\sigma_{q \Phi}^{\infty}(T) \subseteq\{\lambda \in \mathbb{C}:|\lambda|=1\} .
$$




\section{REFERENCES}

1. M. Berkani, A. Arroud, B-Fredholm and spectral properties for multipliers in Banach algebras, Rendiconti Circolo Matematico di Palermo. Serie II 55 (2006), 385-397.

2. M. Burgos, A. Kaidi, M. Mbekhta, and M. Oudghiri, The descent spectrum and perturbations, Journal of Operator Theory 56 (2006), 259-271.

3. M. Benharrat, A. Ammar, B. Messirdi, On the Kato, semi-regular and essentially semi-regular spectra, Functional Analysis, Approximation and Computation 6 (2014), no. 2, 9-22.

4. Z. Garbouj, H. Skhiri, Essential ascent of closed operator and some decomposition theorems, Commun. Math. Anal. 16 (2014), 19-47.

5. S. Grabiner, Uniform ascent and descent of bounded operators, J. Math. Soc. Japan 34 (1982), $317-337$.

6. J. J. Koliha, M. Mbekhta, V. Müller, Pak Wai Poon, Corrigendum and addendum: "On the axiomatic theory of spectrum II", Studia Math. 130 (1998), no. 2, 193-198.

7. J. P. Labrousse, Les opérateurs quasi-Fredholm: une généralisation des opérateurs semiFredholm, Rendiconti Circolo Matematico di Palermo. Serie II, XXIX (1980), 161-258.

8. D. C. Lay, Spectral analysis using ascent, descent, nullity, and defect, Math. Ann. 184 (1970), 197-214.

9. M. Mbekhta, Ascente, descente et spectre essentiel quasi-Fredholm, Rendiconti Circolo Matematico di Palermo. Serie II, XLVI (1997), 175-196.

10. V. Müller, Spectral Theory of Linear Operators and Spectral Systems in Banach Algebras, Operator Theory Adv. Appl. 139, (2nd edition), Birkhäuser, Basel, 2007.

11. A. E. Taylor, Introduction to Functional Analysis, John Wiley \& Sons Inc., New York, 1958.

Institut Supérieur des Sciences Appliquées et de Technologie de Kairouan, Département de Mathématiques, Avenue Beit El Hikma, 3100 Kairouan, Tunisia

E-mail address: zied.garbouj.fsm@gmail.com

Faculté des Sciences de Monastir, Département de Mathématiques, Avenue de l’environnement, 5019 Monastir, TUNisia

E-mail address: haikel.skhiri@gmail.com, haikel.skhiri@fsm.rnu.tn

Received 21.04.2019; Revised 02.01.2020 